\title{
Applications of Non-invasive Neuromodulation for the Management of Disorders Related to COVID-19
}

\section{OPEN ACCESS}

Edited by:

David Charles Good,

Penn State Milton S. Hershey Medical

Center, United States

Reviewed by:

Antonino Naro,

Centro Neurolesi Bonino Pulejo (IRCCS), Italy Wayne Feng,

Duke University Medical Center United States

*Correspondence: Abrahão Fontes Baptista a.baptista@ufabc.edu.br

tThese authors have contributed equally to this work

Specialty section:

This article was submitted to

Neurorehabilitation,

a section of the journal

Frontiers in Neurology

Received: 17 June 2020 Accepted: 11 September 2020 Published: 25 November 2020

Citation:

Baptista AF, Baltar A, Okano AH, Moreira A, Campos ACP,

Fernandes $A M$, Brunoni $A R$,

Badran BW, Tanaka C, de Andrade DC, da Silva Machado DG,

Morya E, Trujillo E, Swami JK, Camprodon JA, Monte-Silva K,

Sá KN, Nunes I, Goulardins JB, Bikson M, Sudbrack-Oliveira P, de

Carvalho P, Duarte-Moreira RJ,

Pagano RL, Shinjo SK and Zana Y (2020) Applications of Non-invasive Neuromodulation for the Management

of Disorders Related to COVID-19.

Front. Neurol. 11:573718.

doi: 10.3389/fneur.2020.573718

\begin{abstract}
Abrahão Fontes Baptista ${ }^{1,2,3,4 * \dagger}$, Adriana Baltar ${ }^{2,5}$, Alexandre Hideki Okano 1,2,3,6†, Alexandre Moreira ${ }^{7}$, Ana Carolina Pinheiro Campos $^{8}$, Ana Mércia Fernandes ${ }^{9}$, André Russowsky Brunoni ${ }^{10,11}$, Bashar W. Badran ${ }^{12}$, Clarice Tanaka ${ }^{2,4,13}$, Daniel Ciampi de Andrade ${ }^{2,9}$, Daniel Gomes da Silva Machado ${ }^{14}$, Edgard Morya ${ }^{15 t}$, Eduardo Trujillo ${ }^{1,2}$, Jaiti K. Swami ${ }^{16}$, Joan A. Camprodon ${ }^{17}$, Katia Monte-Silva ${ }^{2,18}$, Katia Nunes Sá ${ }^{2,19}$, Isadora Nunes ${ }^{20}$, Juliana Barbosa Goulardins ${ }^{2,4,7,21}$, Marom Bikson ${ }^{16}$, Pedro Sudbrack-Oliveira ${ }^{22}$, Priscila de Carvalho ${ }^{13}$, Rafael Jardim Duarte-Moreira ${ }^{1,2}$, Rosana Lima Pagano ${ }^{8 \dagger}$, Samuel Katsuyuki Shinjo ${ }^{23+}$ and Yossi Zana ${ }^{1 \dagger}$
\end{abstract}

${ }^{1}$ Center for Mathematics, Computation and Cognition, Federal University of ABC, São Bernardo do Campo, Brazil, ${ }^{2}$ NAPeN Network (Rede de Núcleos de Assistência e Pesquisa em Neuromodulação), Brazil, ${ }^{3}$ Brazilian Institute of Neuroscience and Neurotechnology Centros de Pesquisa, Investigação e Difusão - Fundação de Amparo à Pesquisa do Estado de São Paulo (BRAINN/CEPID-FAPESP), University of Campinas, Campinas, Brazil, ${ }^{4}$ Laboratory of Medical Investigations 54 (LIM-54), São Paulo University, São Paulo, Brazil, ${ }^{5}$ Specialized Neuromodulation Center-Neuromod, Recife, Brazil, ${ }^{6}$ Graduate Program in Physical Education, State University of Londrina, Londrina, Brazil, ${ }^{7}$ School of Physical Education and Sport, University of São Paulo, São Paulo, Brazil, ${ }^{8}$ Laboratory of Neuroscience, Hospital Sirio-Libanes, São Paulo, Brazil, ${ }^{9}$ Centro de Dor, LIM-62, Departamento de Neurologia, Faculdade de Medicina FMUSP, Universidade de São Paulo, São Paulo, Brazil, ${ }^{10}$ Serviço Interdisciplinar de Neuromodulação, Laboratório de Neurociências (LIM-27), Instituto Nacional de Biomarcadores em Neuropsiquiatria, São Paulo, Brazil, "1 Instituto de Psiquiatria, Hospital das Clínicas HCFMUSP, Faculdade de Medicina, Universidade de São Paulo, São Paulo, Brazil, ${ }^{12}$ Department of Psychiatry, Medical University of South Carolina, Charleston, SC, United States, ${ }^{13}$ Instituto Central, Hospital das Clínicas HCFMUSP, Faculdade de Medicina, Universidade de São Paulo, São Paulo, Brazil, ${ }^{14}$ Graduate Program in Collective Health, Federal University of Rio Grande do Norte, Natal, Brazil, ${ }^{15}$ Edmond and Lily Safra International Neuroscience Institute, Santos Dumont Institute, Macaiba, Brazil, ${ }^{16}$ Department of Biomedical Engineering, The City College of New York of CUNY, New York, NY, United States, ${ }^{17}$ Laboratory for Neuropsychiatry and Neuromodulation, Massachusetts General Hospital and Harvard Medical School, Boston, MA, United States, ${ }^{18}$ Applied Neuroscience Laboratory, Universidade Federal de Pernambuco, Recife, Brazil, ${ }^{19}$ Escola Bahiana de Medicina e Saúde Pública, Salvador, Brazil, ${ }^{20}$ Department of Physiotherapy, Pontifícia Universidade Católica de Minas Gerais, Betim, Brazil, ${ }^{21}$ Universidade Cruzeiro do Sul (UNICSUL), São Paulo, Brazil, ${ }^{22}$ Faculdade de Medicina FMUSP, Universidade de São Paulo, São Paulo, Brazil, ${ }^{23}$ Division of Rheumatology, Faculdade de Medicina FMUSP, Universidade de São Paulo, São Paulo, Brazil

Background: Novel coronavirus disease (COVID-19) morbidity is not restricted to the respiratory system, but also affects the nervous system. Non-invasive neuromodulation may be useful in the treatment of the disorders associated with COVID-19.

Objective: To describe the rationale and empirical basis of the use of non-invasive neuromodulation in the management of patients with COVID-10 and related disorders.

Methods: We summarize COVID-19 pathophysiology with emphasis of direct neuroinvasiveness, neuroimmune response and inflammation, autonomic balance and neurological, musculoskeletal and neuropsychiatric sequela. This supports the development of a framework for advancing applications of non-invasive neuromodulation in the management COVID-19 and related disorders. 
Results: Non-invasive neuromodulation may manage disorders associated with COVID19 through four pathways: (1) Direct infection mitigation through the stimulation of regions involved in the regulation of systemic anti-inflammatory responses and/or autonomic responses and prevention of neuroinflammation and recovery of respiration; (2) Amelioration of COVID-19 symptoms of musculoskeletal pain and systemic fatigue; (3) Augmenting cognitive and physical rehabilitation following critical illness; and (4) Treating outbreak-related mental distress including neurological and psychiatric disorders exacerbated by surrounding psychosocial stressors related to COVID-19. The selection of the appropriate techniques will depend on the identified target treatment pathway.

Conclusion: COVID-19 infection results in a myriad of acute and chronic symptoms, both directly associated with respiratory distress (e.g., rehabilitation) or of yet-tobe-determined etiology (e.g., fatigue). Non-invasive neuromodulation is a toolbox of techniques that based on targeted pathways and empirical evidence (largely in nonCOVID-19 patients) can be investigated in the management of patients with COVID-19.

Keywords: coronavirus, COVID-19, non-invasive vagus nerve stimulation, taVNS, tDCS, TMS, neuromodulation, NIBS

\section{INTRODUCTION}

The first cases of novel coronavirus disease (COVID-19) were reported in Wuhan, China, in December 2019 (1). The disease caused by the new severe acute respiratory syndrome coronavirus 2 (SARS-CoV-2) spread rapidly worldwide and affected more than three million people, and killed more than 750 thousand up to July 2020 (1). The virus spreads by droplet transmission and via direct contact with people while they are infectious in both the pre-symptomatic and symptomatic phases, although a potential transmission via fecal, urine, aerosol, and fomite have been reported $(2,3)$.

COVID-19 presents a variety of clinical symptoms from asymptomatic to severe respiratory dysfunction and death. Key symptoms include fever, anosmia, ageusia, vertigo, nausea, headache, lower limb pain, cough, fatigue, shortness of breath, sore throat, arthralgia, chills, vomiting, and others. In more severe cases, the infection can cause pneumonia, severe acute respiratory syndrome, and kidney failure (4), and on rare occasions, stroke (5, 6), and encephalitis (7-9). Systemic issues such as coagulation disturbances/thrombosis $(10,11)$ and cytokine storm $(12,13)$ are also relevant, especially to understand how COVID-19 would be associated with nervous system pathology. Risk factors to severe complications are age (more than 65 years old), and comorbidities, such as systemic arterial hypertension, chronic obstructive pulmonary disease, cardiopathies, morbid obesity, diabetes mellitus, and cancer (14, 15). COVID-19 may not only be restricted to the respiratory system but would possibly affect the peripheral (PNS) and central (CNS) nervous systems which appear to have an influence on morbidity and mortality (16). However, this topic is still a matter of debate.

SARS-CoV was detected in the cerebral cortex and hypothalamus of six out of eight confirmed patients, but not in unconfirmed or control patients (17). The virus may invade the
CNS via olfactory nerves, and from the guts via the vagus nerve, reaching brainstem nuclei associated with cardio-respiratory control (18), and thalamus, causing autonomic dysfunction and/or neurogenic respiratory failure (19). Inflammatory waves and particles may reach in the supraspinal nuclei in the brainstem and trigger "the inflammatory reflex," a pathway that has both immunosensing and immunosuppressive functions (20). Thus, the neuroinvasive potential of the SARS-CoV-2 could be related to the severity of some cases $(21,22)$, and also extend the impact of the disease on cognitive and behavioral aspects. While a growing body of evidence suggests that COVID-19 is associated with neurological diseases $(2-4,23)$, the potential neuroinvasiveness of the virus and its relation to COVID-19 pathophysiology continues to be deliberated. There are few documented cases of encephalitis (24). It is not clear if CNS pathological findings are a consequence of direct virus infection or consequent to hypoxia (25), and the controversy of SARS-CoV-2 neuroinvasiveness is not resolved

Although it is not clear if COVID-19 affects the nervous system directly, and how this would impact the severity of some cases, the inflammatory nature of the disease is well-recognized (26-29). Despite the uncertainty of the direct involvement of nervous system pathology in the pathophysiology of COVID-19, it is clear that patients present other necessities such as respiratory care and rehabilitation (22, 30-32) and the management of fatigue, and pain (33, 34), for instance. Strategies to control inflammation usually include pharmacological approaches (35-37), but especially given incomplete efficacy and complications in many patients, alternative treatments approaches are relevant. Non-invasive brain stimulation (38-40) and vagus nerve stimulation (41) have the potential to reduce inflammation. These techniques can be used in the management of psychiatric symptoms associated with the COVID-19 pandemic (39, 42, 43). Noninvasive neuromodulation has also shown to be a potent resource 
in cognitive and physical rehabilitation $(44,45)$ and could serve additional goals in the management of COVID-19 patients (30).

Here, we review aspects of the SARS-CoV-2 pathophysiology and its relation to the immune response, autonomic balance, neurological, musculoskeletal and respiratory symptoms, and neuropsychiatric aspects of COVID-19. We highlight the potential applications of non-invasive neuromodulation techniques such as transcranial direct current stimulation (tDCS), repetitive transcranial magnetic stimulation (rTMS), and vagus nerve stimulation (VNS) in the treatment of patients with disorders related to COVID-19. We link specific noninvasive neuromodulation techniques to the management of targeted disease aspects.

Non-invasive neuromodulation may manage disorders associated with COVID-19 through four pathways:

(1) Direct infection mitigation through the stimulation of regions involved in the regulation of systemic antiinflammatory responses and/or autonomic responses and prevention of neuroinflammation and recovery of respiration;

(2) Amelioration of COVID-19 symptoms of musculoskeletal pain and systemic fatigue;

(3) Augmenting cognitive and physical rehabilitation following critical illness; and

(4) Treatment of outbreak-related mental distress including neurological and psychiatric disorders exacerbated by surrounding psychosocial stressors related to COVID-19.

The above pathways may be linked. For example, systemic inflammation can occur alongside brain inflammation and fatigue and/or pain, which will all indirectly aggravate psychiatric symptoms (e.g., isolation provoked anxiety). These pathways both in the context of COVID-19 etiology and specific noninvasive neuromodulation therapeutic targets are addressed here, alongside practical considerations for $\mathrm{NiN}$ deployment.

\section{MATERIALS AND METHODS}

This targeted view (5) was steered by groups of authors involved with research in the fields of inflammation and immune responses to infections, autonomic nervous system activity, neurology, psychiatry, psychology, physiotherapy, rheumatology, neuroscience, bioengineering, and non-invasive neuromodulation. All the groups reviewed the literature using relevant keywords in their specific areas, in search for relevant texts, mainly peer-reviewed articles, to describe a rationale on the use of $\mathrm{NiN}$ in the treatment of patients with disorders related to COVID-19. The key problems to be addressed were described by clinicians in reference hospitals in Brazil dealing with COVID-19 patients, and were summarized as: (a) how to help patients who arrive at hospitals with high levels of inflammatory markers, many of which are sent after a short time to intensive care units, and some die after a few days? (b) how to help weaning from mechanical ventilation, intra-hospital rehabilitation, and discharge of patients with COVID-19, who seem to present a slower pattern of recovery, compared to patients without
COVID-19? (c) how to approach patients and health teams who are presenting elevated levels of distress, including outbreaks of anxiety; (d) how to prepare for the post-COVID-19 phase, where some patients will need to be rehabilitated because of the consequences of the infection?

After searching the peer-reviewed and pre-print literature and summarizing their findings, key authors from each group joined to integrate their findings, aiming to describe which pathophysiological mechanisms would be approached by the use of NiN. Finally, three authors (BWB, JAC, and MB) externally reviewed the manuscript. The non-invasive neuromodulation tools found to be of relevance were tDCS, rTMS, and VNS. The basis for its use and practical aspects of the application in patients with COVID-19 are described.

\section{Rationale for the Use of Non-invasive Neuromodulation Techniques in the Treatment of COVID-19 Patients}

This section presents the theoretical basis that would underpin the use of non-invasive neuromodulation techniques in the management of COVID-19 patients. The potential neuroinvasiveness of COVID-19 represents the first avenue where these nervous system stimulation techniques would act in the control of the disease. In addition, non-invasive neuromodulation can also stimulate the neuroimmune response to the virus, a key factor to determine the severity of the symptoms. Non-invasive neuromodulation techniques may also be useful in the physical and cognitive rehabilitation of the patients, as well as in the management of the mental health both in patients and healthcare teams.

\section{Potential Neuroinvasiveness of COVID-19}

SARS-CoV-2, such as MERS-CoV and SARS-CoV can be transmitted through infectious droplets, via angiotensin-2 converting enzyme (ACE2) and transmembrane serine protease 2 (TMPRSS2), which are important to cell viral invasion (46-48). SARS-CoV-2 can directly access the central nervous system (CNS) through the circulation or cranial nerves and the olfactory bulb $(18,49)$, by synapse-connection (Figure 1) (50-52). In addition, direct endocytotic infection (similar to that demonstrated for the ZIKA and TBEV viruses) may also be a pathway for CNS invasion. Once within the CNS, coronaviruses affect astrocytes, neuroblasts, and neurons (5355). The neurobiological mechanism involves a direct binding of SARS-CoV-2 to the ACE2 receptor leading to a fall in $\mathrm{ACE} 2$, which is responsible for mediating neuroinflammation, neurodegeneration, and neurotoxicity processes related to CNS disorders. Invasion of the brainstem may be also clinically relevant, since the nucleus of the solitary tract (NTS) and nucleus ambiguous are crucial for the maintenance of cardiorespiratory homeostasis $(22,51)$. Afferents of the vagus nerve convey peripheral inflammation information to the CNS, specifically in the medullary NTS and nucleus ambiguous $(56,57)$. The NTS responds to hypoxia and hypercapnia by activating or inhibiting the sympathetic activity (58-61). This autonomic response is a 


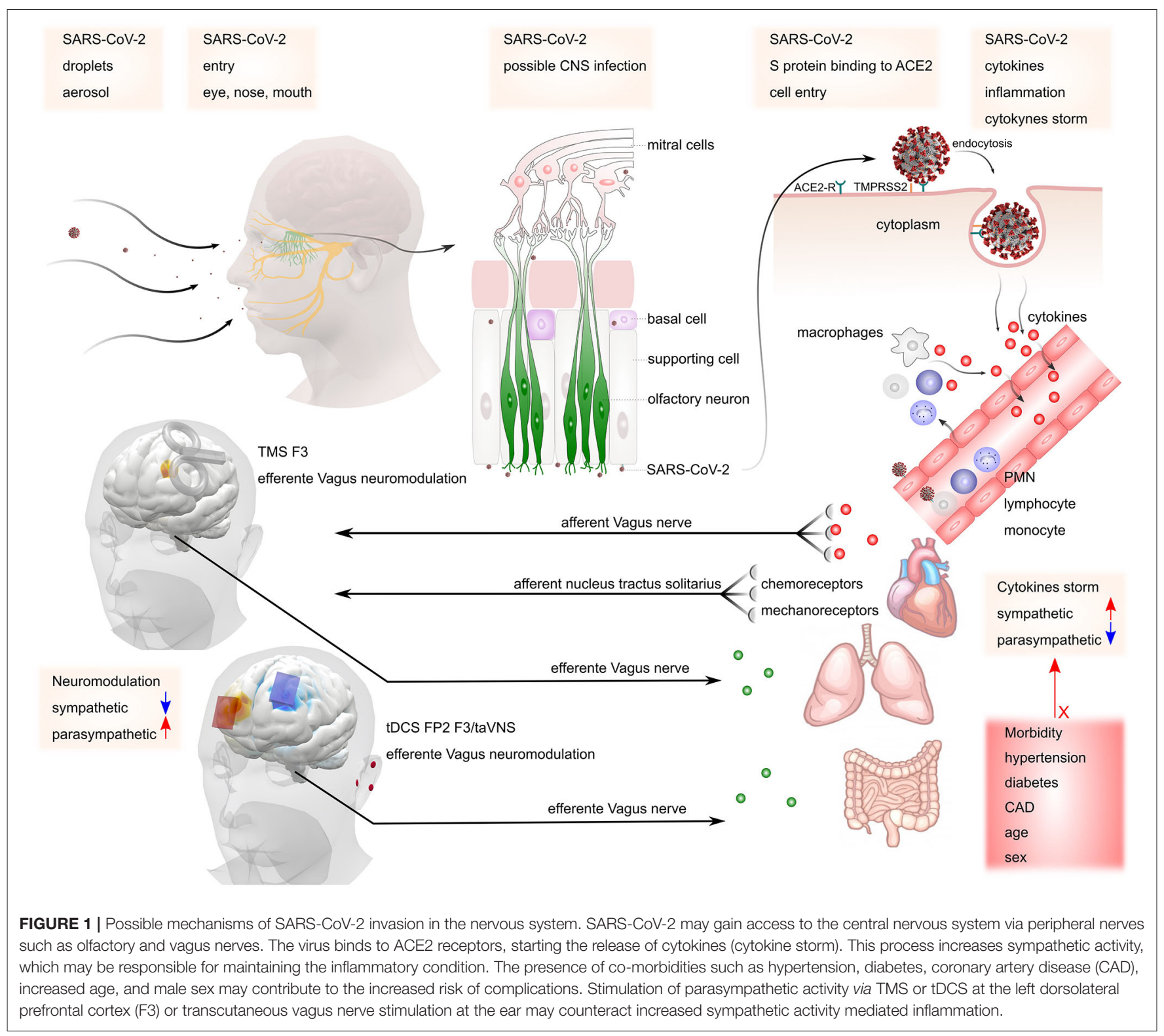

powerful regulator of the innate and adaptive immune system $(62,63)$.

The sympathetic nervous system promotes pro-inflammatory responses, via catecholamine release and beta-adrenergic stimulation, and the parasympathetic nervous system promotes anti-inflammatory effects (64). Besides, primary and secondary immune organs have substantial sympathetic innervation and almost all immune cells express receptors for neurohormones and neurotransmitters (65). These factors suggest that COVID-19 may be a systemic disease associated with systemic inflammation and trigger a massive neuroinflammatory response, manifested by reactive astrogliosis and microglial activation (66).

Although respiratory (nasal/oral cavity, pharynx, larynx) to nervous system transmission is still under investigation in the case of COVID-19 pandemic, the reports of neurological symptoms in infected patients support the potential neuroinvasiveness of SARS-CoV-2. Patients with COVID19 in hospitals of Wuhan presented acute CNS symptoms, such as dizziness, headache, impaired consciousness, acute cerebrovascular disease, ataxia, and convulsions (67). Earlier studies also reported the presence of SARS-CoV within the brain of infected individuals $(17,68)$, and in the brainstem of animal models $(17,68,69)$, supporting the evidence that COVID-19 affects the CNS (22), and also a possible bidirectional communication with the immune system (63). Moreover, other short-term neurological symptoms observed in COVID-19 patients could also be a manifestation of CNS invasion, such as high-grade fever, hypoxia, respiratory, and metabolic acidosis at an advanced stage of the disease (16). 
However, a recent study reported inconsistent results on SARS-CoV-2 invasion of the CNS, and one cannot rule out that all the above-described neurological symptoms could be secondary to a non-neurological process (e.g., general inflammation, cytokine storm, hemodynamic shock, systemic thrombotic phenomena). Characterizing the symptoms and etiology of COVID-19 neurological manifestation is complex and subject to ongoing studies, including post-pandemic consequences of the infection, such as encephalitis $(70,71)$, acute flaccid paralysis (72), acute disseminated encephalomyelitis (19, $73,74)$, neuropsychiatric and cognitive impairments consequent of neuroinflammation together with prolonged hypoxia (18). A recent report suggests that neurological manifestations in COVID-19 patients should be classified as confirmed, probable or possible/suspected based in a WHO classification (6). This effort will probably be useful to shed light into the clarification of the involvement of the nervous system pathology into COVID19. Non-invasive neuromodulation techniques are currently used and trialed for the management of a broad range neurological diseases $(7,8)$, and are thus candidates in the management of neurological manifestations of COVID-19-as considered later in this article.

\section{Immune Response to COVID-19}

The innate immune system can recognize lipopolysaccharides, viral antigens, and viral genomes through pattern recognition receptors (PRRs), leading to the activation of intrinsic signaling pathways and the production of pro-inflammatory and antiinflammatory cytokines (75-78). An immune response initiates after a virus invading the body (host) is recognized by the host innate immune system through PRRs $(79,80)$. The expression of inflammatory factors, maturation of dendritic cells, and synthesis of type I interferons (IFNs) are induced by the virus, limiting the spreading of the virus while stimulating macrophages (81).

Notwithstanding this innate immune response to the virus, Lu et al. (82) argued that the N protein of SARS-CoV could aid the virus in "escaping" from the expected immune responses. After the initial activation of the innate immunity, the adaptive immune response is involved in a battle against the virus (82). The T lymphocytes (T-cells; CD3+, CD4+, and CD8+) and B-cells (CD19+, CD20+, CD22+), the cellular adaptive components, play an important and complex role in the body defense. For example, CD4+ T-cells stimulate B-cells to produce virus-specific antibodies, and CD8+ T-cells have the function to kill the virus-infected cells. Moreover, the helper cells will produce pro-inflammatory cytokines to aid in the defense. Indeed, humoral immunity is also essential in fighting against the virus in order to combat the viral infection $(82,83)$. However, SARS-CoV-2 can inhibit $\mathrm{T}$ cell functions by inducing apoptosis of T-cells, and an overreaction of the immune system could exaggerate elevating the number of free radicals locally that in turn could lead to damages to the lungs, organs, and. to multiorgan failure and even death (84).

A cytokine storm results from an overreaction of the immune system in SARS and MERS patients (84-86), which releases excessively free radicals and causes acute respiratory distress syndrome and multiple organ failure (87). Therefore, a cytokine storm is a systemic inflammatory response due to a release of cytokines such as TNF $\alpha$, IL-1 $\beta$, IL-2, IL-6, IFN $\alpha$, IFN $\beta$, IFN $\gamma$, and MCP-1 (80), and activated macrophages responsible for pro-inflammatory mediators such as cyclooxygenase and nuclear factor-kappa B (88). Sustained inflammatory responses may be related to the critical conditions of COVID-19 patients, whereas those patients admitted in the intensive care unit had higher plasma levels of TNF $\alpha$, IL-2, IL-7, IL-10, GSCF, IP10, MCP-1, and MIP1A, indicating that the cytokine storm is related to disease severity $(84,85,89)$.

Therapeutic immunosuppression is fundamental and critical in the treatment of cytokine storms, notably, in COVID-19 severe conditions. Mehta et al. (12) reported a subgroup of patients with severe COVID-19 that might have cytokine storm syndrome. Huang et al. described patients with COVID-19 in Wuhan (China), presenting high amounts of IL-1 $\beta$, IFN $\gamma$, IP10, and MCP-1, probably leading to activated Th1 cell responses $(12,89)$. Huang et al. (89) also described that SARS-CoV-2 induces an increased secretion of Th2 cytokines (e.g., IL-4 and IL-10) that suppress inflammation, differently to those observed from SARS$\mathrm{CoV}$ infection. These mechanisms may also be related to the genesis of acute cerebrovascular disease and acute hemorrhagic necrotizing encephalopathy (90), resulting from blood-brainbarrier damage (91). Indeed, data from mouse models suggest that the influenza virus can aggravate ischemic brain injury by triggering a cytokine cascade (92). As all the above mentioned immune responses are linked to peripheral nervous system (PNS) and CNS activity through autonomic responses, nervous system activity may be a key factor in the response to infection, which could in turn be modulated by non-invasive neuromodulation techniques especially through vagus nerve stimulation.

\section{Autonomic Response in COVID-19 Infection}

The vagus nerve releases acetylcholine (ACh) in the periphery to activate parasympathetic responses in target organs throughout the body such as lowering heart rate HR) and myocardial contractility in the heart (93). There are numerous downstream effects of ACh release in the periphery, such as activating $\alpha 7$ nicotinic ACh receptors ( $\alpha 7 \mathrm{nAChR}$ ) on macrophages (94-99), inhibiting the production of IL-1, IL-6, IL-18, and HMBG1 (100102) in several tissues and organs, such as the spleen, intestine, liver, heart, and lung $(20,103)$. The $\alpha 7 \mathrm{nAChR}$ has an important role in the control of inflammation since $\alpha 7 \mathrm{nAChR}$-deficient mice show higher levels of pro-inflammatory cytokines in blood, spleen, and liver after endotoxin when compared to wild-type mice (104). In addition to that, ACh is also released by $\mathrm{T}$ and $B$ cells with autocrine responses such as IL-2 release and T cell proliferation $(105,106)$, corroborating its importance in the inflammatory modulation.

Vagal activity is correlated with decreased inflammatory markers (e.g., IL-6, C-reactive protein) (107, 108). In experimental models, lesioning the vagus nerve (vagotomy) exacerbates the inflammatory response in colitis, pancreatitis, viral myocarditis, and sepsis (109-111). It also increases the synthesis of pro-inflammatory lipid mediators, while decreasing pro-resolving mediators such as netrin-1 and specialized proresolving mediators (SPMs) (112), which decrease the resolution 
of bacteria inflammation $(113,114)$. In addition, vagotomy not only decreases $\mathrm{ACh}$ release but also catecholamines $(113,114)$, which likewise have an important role in controlling inflammation (115). Deficiency in T- and B-cells related to increasing in alternatively activated immune cells lead to exacerbated viral replication, prolonged inflammatory responses both systemic and locally, induction of procoagulant factors, hemodynamic changes, ischemia and thrombosis leading to poor outcomes (116-118). The presence of SARS-CoV-2 in the brainstem, independently of the infection detected in the lungs, induces neuronal loss and dysfunction (119), which may be associated with an autonomic imbalance with a decrease of ACh and catecholamine release in the periphery. It is noteworthy that cardiovascular disease and diabetes, risk factors for worse prognostic and death by the COVID-19 (120-122), are characterized by decreased autonomic function. This condition may be relevant in some COVID-19 patients who present a high inflammatory profile and could be targeted by strategies to increase vagus activity, which have already been shown to regulate autonomic function in patients with cardiovascular diseases and diabetes.

\section{Musculoskeletal Symptoms and Fatigue in COVID-19} Musculoskeletal symptoms and fatigue in COVID-19 may also represent the affection of nervous and/or immune function. Skeletal muscle symptoms were shown to be common in individuals with COVID-19 (67). Different meta-analyses of COVID-19 clinical characteristics have reported an incidence of generalized myalgia and/or fatigue that ranges from 35.5 to $42.5 \%(33,34,123)$. Muscular symptoms are the third or fourth more frequent manifestation reported by individuals. Also, these symptoms should be taken into account for diagnostic criteria, since individuals with severe infection are more likely to present non-typical symptoms first (67). Individuals with muscular symptoms presented an increased inflammatory response, including higher levels of C-reactive protein (67). These findings are indicative of muscle injury, although the lysis of striated muscle is considered as a rare complication of COVID19 (34).

There are two proposed mechanisms to explain myalgia and fatigue. The first is that the inflammatory response is not only the consequence of muscle injury but also the cause. Not only individuals with a more severe infection have more incidence of muscle symptoms, but also those who present muscle symptoms usually have multiple organ lesions (67). Altogether, there is some evidence that systemic inflammation can lead to muscle fiber necrosis (124). The second mechanism is related to the ACE2 receptor targeted by the virus and also found in muscle cells $(67,124)$. It is hypothesized that COVID-19 could injure directly the muscle tissue, but there is no evidence to substantiate this theory, and it comes from studies of SARS. Two studies conducted an analysis of post mortem muscle tissue of patients who died with SARS $(68,125)$. One of them did not find any evidence of the virus in muscle tissue (68). The other found focal myofiber necrosis but with small quantities of inflammatory infiltration (125). Authors of the second study argue about not being able to remove the confounding influence of mechanical ventilation used by these patients, and its side effects on their findings. Probably, the systemic inflammatory response is the main cause of muscle symptoms in individuals with COVID-19. Muscle fatigue and weakness could hamper respiratory function and become a vicious cycle with the aid of mechanical ventilation devices, which per se, can cause more weakness (125).

\section{Psychiatric Symptoms and the Mental Health Outbreak Related to COVID-19}

The evidence of the impact of this pandemic on mental health is evolving. An online survey of 714 Chinese patients with stable COVID-19 disease reported a $96.2 \%$ prevalence of significant post-traumatic stress symptoms (126). As for the general population, a survey of residents of Wuhan and surrounding cities, the epicenter of the China outbreak, the prevalence of posttraumatic stress symptoms was $7 \%$ as assessed up to 2 weeks after mandatory quarantine for all citizens was implemented. Women and those with sleep complaints were reported to be at increased risk (127). As for protective factors of anxiety symptoms, family income stability, and living with parents were protective (128). Among healthcare professionals, 28\% of nurses and physicians working in Wuhan were found to have either moderate or severe symptoms in the domains of depression, anxiety, insomnia, and distress (129).

\section{Potential Use of Non-invasive Neuromodulation on COVID-19 Related Disorders}

In the previous section we described how COVID-19 may affect or be mediated by the nervous system and immune activity, aspects that can be targeted by non-invasive neuromodulation techniques in order to manage the disease. We now present the rationale specific uses of these techniques in the management of COVID-19 patients, relying largely on evidence from relevant non-COVID-19 populations, as direct trials of non-invasive neuromodulation in COVID-19 patients remain limited or are ongoing.

The possible presence of an autonomic imbalance in COVID19 and the importance of vagus nerve activity in the control of inflammation may represent key features to the use of $\mathrm{NiN}$ in the treatment of COVID-19 patients, markedly those with high levels of inflammatory profile. Vagus nerve activity can be increased via the cerebral cortex through areas that modulate it indirectly such as the left dorsolateral prefrontal cortex (DLPFC) (130), corresponding to the $\mathrm{F} 3$ position of the 10-20 International EEG System, or temporal cortices. Also, the vagus nerve innervates the ear, mainly the pinna of the outer ear (131), making it possible to stimulate these areas transcutaneously to influence vagus activity $(9,10)$. In this section, we will review the most promising, readily available $\mathrm{NiN}$ approaches that modulate the central and peripheral immune response. At the same, NiN may be useful in the control of musculoskeletal psychiatric symptoms and through the same or even different cortical targets as those used in the control of inflammation. The subsequent sections will present the basis for the use of $\mathrm{NiN}$ in the treatment of COVID-19 patients using techniques such as rTMS, tDCS, and 
A

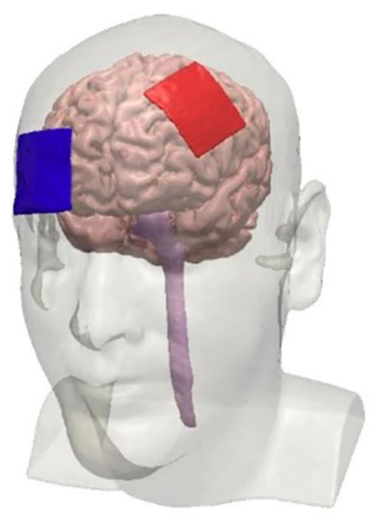

D

(a)

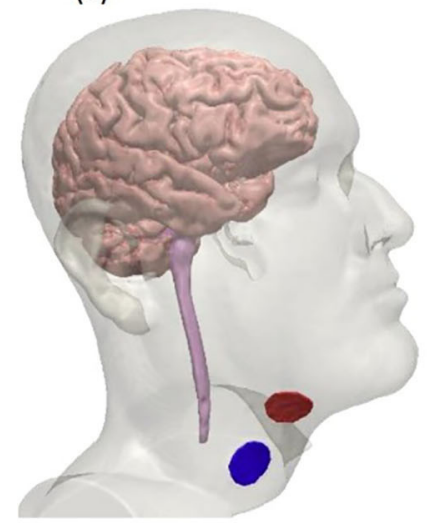

B

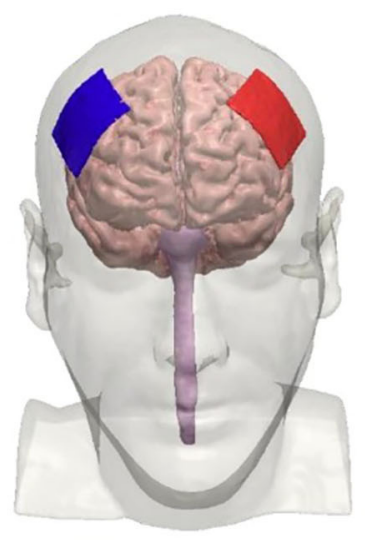

(b)

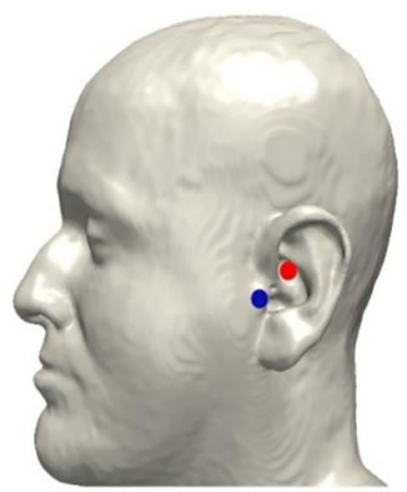

C

(a)

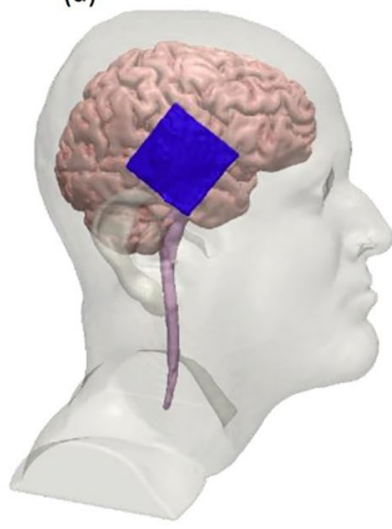

E

(a)

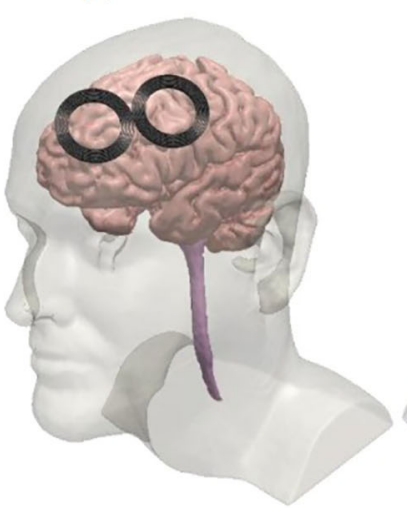

(b)

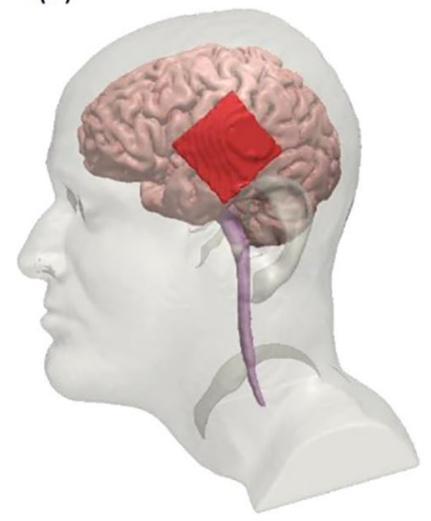

(b)

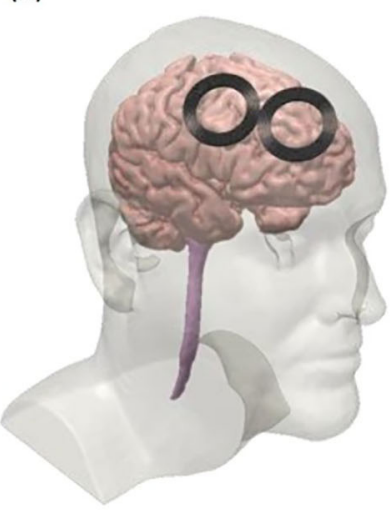

FIGURE 2 | Electrode configurations for non-invasive tDCS, VNS, and rTMS following the 10-20 EEG system. (A) Unilateral tDCS with anode positioned over F3 and cathode over Fp2 on the scalp to modulate the left dorsolateral prefrontal cortex (DLPFC). (B) tDCS using a bifrontal montage to perform anodal stimulation on left DLPFC where the anode is positioned over F3 and cathode is positioned over F4. (C) Anodal tDCS to stimulate the temporal cortex using a bifrontal configuration where the cathode is positioned over T4 and the anode over T3 as seen in (a,b), respectively. (D) Non-invasive vagus nerve stimulation by modulating the cervical branch of the vagus nerve in (a) and the ear in (b). Electrode placement for cervical vagus nerve stimulation is shown in (a). Electrodes are placed at the tragus and the cymba conchae of the left ear to perform unilateral taVNS as shown in (b). (E) rTMS using a figure-8 coil positioned over F3 to stimulate the left DLPFC suggested for high-frequency protocol is shown in (a). Right DLPFC is stimulated using the low-frequency rTMS protocol by placing the coils over F4 as shown in (b).

vagus nerve stimulation directed to the DLPFC, motor cortex, and where the vagus nerve is superficially accessible (Figure 2 ).

\section{Left Dorsolateral Prefrontal Cortex Neuroimmune Modulation With TMS or tDCS}

The vagus nerve is responsible for the parasympathetic innervation of the heart; its stimulation decreases heart rate (HR), and interferes with heart rate variability (HRV) (132, 133). This phenomenon was also observed when stimulating other areas of the CNS, such as the DLPFC (134), perigenual, and mid-anterior cingulate cortex (pgCC and maCC) (135, 136), which lead researchers to suggest that those cortical areas modulate vagal activity.
Studies with transcranial magnetic stimulation (TMS) have helped elucidate the relationship between the DLPFC and vagus nerve activity. Iseger et al. (134) applied trains of highfrequency $10 \mathrm{~Hz}$ rTMS over 10 cortical regions aiming to identify which regions would affect HR. They found that 20$40 \%$ of the participants presented decreased HR and heart rate variability (HRV) with stimulation of the DLPFC, either left (F3, FC3; 10-20 EEG System) or right (F4, FC4; 10-20 EEG System). Interestingly, stimulation of the motor (C3, C4-1020 EEG System) and parietal (Pz-10-20 EEG System) cortices showed opposite effects. Effects were more pronounced in the right DLPFC, which is contrary to other studies showing that stimulation of the left, but not the right DLPFC changes HRV (137). The variability found in these studies is probably because of individual patterns of connectivity between the DLPFC and 
other cortical and subcortical structures. As an example, in a TMS/fMRI, Iseger et al. (134) and Vink et al. (138) found that only four under 10 participants had the subgenual cingulate cortex activated by stimulation of the DLPFC.

The anti-inflammatory effects of DLPFC stimulation support the idea of DLPFC/vagus connectivity. Aftanas et al. (139) applied dual-target rTMS to the motor cortex (bilaterally; $10 \mathrm{~Hz} ; 100 \%$ of resting motor threshold; 4,000 pulses) and to the left prefrontal cortex (DLPFC; $10 \mathrm{~Hz}, 110 \%$ of resting motor threshold; 3,000 pulses) for 20 days in patients with Parkinson disease. They reported significant down-regulation of the spontaneous production of pro-inflammatory cytokines. Although not tested in this study, the effect may be related to increased vagal activity and suggests that the DLPFC would be a potential target in the control of inflammatory cascade in patients with COVID-19.

Transcranial direct current stimulation (tDCS) has also been used to probe HRV and vagal activity. Carvenali et al. stimulated the left DLPFC with anodal tDCS immediately before and during exposure to stress and showed decreased HRV only in the period prior to stress exposure (140). Similar results were found with bifrontal tDCS (141), which raises again the question about the effect of laterality when stimulating the DLPFC with the aim to increase vagus nerve activity.

Taking together, those studies suggest that stimulation of the DLPFC with rTMS or tDCS could be useful to increase vagal activity. The consequent decrease in inflammation with those strategies is speculative. However, as patients with COVID19 also present mood disturbances such as stress and anxiety, targeting the DLPFC would be useful in the control of inflammation and neuropsychiatric problems associated with the infection (see below for neuropsychiatric effects). Unilateral tDCS protocols would target the left DLPFC with the anode positioned over the F3 scalp position (10-20 EEG System), and cathode over the Fp2 scalp position (10-20 EEG System) or another distant location. Typical current intensities of 1-2 mA, for 20-30 min, and electrodes' sizes ranging from $5 \times 5 \mathrm{~cm}$ or $7 \times 5 \mathrm{~cm}$. Bifrontal protocols would position the anode over F2, and cathode over the F4 scalp position (10-20 EEG System) or in the bifrontal "OLE" montage which can optimize current delivery to DLPFC (11-13). Targeted tDCS of DLPFC can be achieved using 4x1-tDCS centered over DLPFC $(142,143)$. Highfrequency rTMS protocols would target the left DLPFC with $10 \mathrm{~Hz}$, trains of 50 pulses, with intertrain intervals of 25-50 s, at $90-120 \%$ of the resting motor threshold, until 3,000 pulses per session, with figure-of-eight coils positioned at the F3 scalp position or using neuronavigation (14). The right DLPFC may be targeted with low-frequency $1 \mathrm{~Hz}$ rTMS, maintaining the same intensity and number of pulses of high-frequency rTMS. More details for rTMS treatment can be found in the study of Pereira et al. (144).

\section{Temporal Cortex Autonomic Modulation With tDCS}

The use of tDCS over the temporal cortex aims to reach the insular cortex, an area beneath the temporal cortex with profuse autonomic and limbic connectivity. Intraoperative electrical stimulation of the left insular cortex increased blood pressure and HR and stimulation of the right insular cortex resulted in opposite effects (145). In addition, left insular cortex lesion resulted in perturbations of the cardiac autonomic function in humans (increased cardiac sympathetic tone and decreased parasympathetic tone) and predisposed individuals toward a pro-arrhythmic state (145). Furthermore, neuroimaging studies have shown the relation between the insular cortex and cardiac autonomic control $(146,147)$, and acute ischemia of the insular cortex was independently associated with poststroke hyperglycemia, which may reflect sympathoadrenal dysregulation, although no evidence of lateralization was found (148). Other studies have suggested a role played by the insular cortex in a phenomenon called post-exercise hypotension (e.g., temporary decrease in blood pressure below pre-exercise values) $(149,150)$. Hence, the temporal cortex has been the target in several studies aiming to modulate cardiac autonomic control or other functions associated with the insular cortex (151-155).

Montenegro et al. (155) assessed the effects of anodal tDCS ( $2 \mathrm{~mA}$ for $20 \mathrm{~min}$ ) over the left temporal cortex on measures of cardiac autonomic control at rest in two groups of healthy adults, a group of athletes and a group of non-athletes. The stimulation improved cardiac autonomic control in athletes but not in untrained individuals, namely parasympathetic activity, increased whereas the sympathetic activity decreased. The authors attributed the specific results to neuroanatomical and functional changes in the brain induced by long-term exercise training (155). Furthermore, Piccirillo et al. (154) demonstrated that anodal tDCS over T3 scalp position (10-20 International EEG System), $2 \mathrm{~mA}$ for $15 \mathrm{~min}$, improved temporal ventricular repolarization dispersion, reduced sinus sympathetic activity and systemic peripheral resistance, and increased vagal sinus activity and baroreflex sensitivity in older ( $>60$ years old; mean age 70 \pm 6 years), but not younger ( $<60$ years old; mean age $36 \pm 11$ years) individuals. It should be noted that older individuals are at increased risk for worse prognosis and death $(120,121,156)$.

Interestingly, besides modulating cardiac autonomic control at rest, tDCS over the left temporal cortex may also modulate autonomic control during exercise $(151,152)$. Okano et al. (152) applied anodal tDCS over T3 scalp position ( $2 \mathrm{~mA}$ for $20 \mathrm{~min}$ ) in a sample of elite cyclists before submitting them to a maximal graded cycling exercise test (e.g., stress test) and found that the stimulation decreased heart rate at submaximal intensities for roughly half of the exercise test duration. These results were also replicated by Kamali et al. (151) who found decreased HR during fatiguing knee extension exercise after concomitant anodal tDCS over T3 and primary motor cortex (M1) (2 mA for $13 \mathrm{~min}$ ) in trained bodybuilders.

Taken together, these results demonstrate that anodal tDCS applied over the temporal cortex may improve autonomic function in healthy individuals at rest and during stressful stimuli (e.g., exercise). Respiratory exercises are being used in patients with COVID-19, and temporal cortex tDCS may be used to increase their effectiveness in restoring respiratory function in these patients. It is suggested that tDCS may be used with the anode positioned at the T3 scalp position, and cathode at the T4 scalp position, with $2 \mathrm{~mA}$ for $20 \mathrm{~min}$, using $5 \times 5 \mathrm{~cm}$ or 5 $\times 7 \mathrm{~cm}$ electrodes, together with exercises directed to respiratory 
function. For targeted temporal cortex tDCS the $4 \mathrm{x} 1 \mathrm{HD}$-tDCS can be used $(142,143)$.

\section{Neuroimmune Modulation Through Transcutaneous Vagus Nerve Stimulation}

The vagus nerve plays a central role in the autonomic nervous system. It mediates major visceral functions such as heart rate, gastrointestinal motility and secretion, pancreatic endocrine and exocrine secretion, hepatic glucose production, and other visceral functions. Furthermore, and most relevant to the current pandemic is that activation of the vagus nerve suppresses immune and inflammatory responses to pathogen invasion and tissue injury (157). Modulating the vagus nerve has been demonstrated to suppress inflammation is being explored as a treatment for pulmonary arterial hypertension and COPD-related bronchoconstriction (ClinicalTrials.gov: NCT01612793).

The vagus nerve may be stimulated invasively and noninvasively. Cervically-implanted vagus nerve stimulation (VNS) activates the parasympathetic system and mediates lymphocytes and macrophages inhibiting pro-inflammatory production $(113,158-160)$, improving survival in experimental sepsis, hemorrhagic shock, ischemia-reperfusion injury, and other conditions of cytokine excess (161). Interestingly, VNS increases dopamine levels, and similarly to $\mathrm{ACh}$, dopamine also shows anti-inflammatory mechanisms by decreasing TNF- $\alpha$ and inflammasome after endotoxins $(113,114)$. VNS not only inhibits the inflammation but also induces the expression of the SPMs, including the lipoxins, resolvins, protectins, and maresins (162). VNS also regulates the SPMs expression, polymorphonuclear infiltration, and the chemokines and cytokines release, which are directly involved in the inflammatory inhibition within the nervous system (162). Hence, the so-called pro-resolution vagal reflex (163), may induce a more efficient resolution of the inflammatory storm in COVID-19 patients, helping also to improve the quality of life and survival expectancy in these patients.

Recently, a non-invasive form of VNS known as transcutaneous VNS (taVNS) has emerged as a promising, non-invasive alternative to its surgically-implanted predecessor. taVNS activates the vagal system by delivering electrical pulses to the auricular branch of the vagus nerve (ABVN) that innervates both left and right ears (164). taVNS is simple and inexpensive to administer, requiring only bipolar electrodes attached to the skin mainly in the tragus and cymba conchae $(131,165)$. A consensus on optimal stimulation parameters is yet to be determined, however, taVNS is generally administered using the following range of waveforms: monophasic or biphasic pulses delivered at $5-25 \mathrm{~Hz}$ pulsed, $\leq 500 \mu \mathrm{S}$ pulse width, $\leq 10 \mathrm{~mA}$ (166). taVNS can be administered either unilaterally (left ear) or bilaterally (left and right ears) at either the left tragus or cymba conchae, for $1 \mathrm{~h}$ sessions (166). The safety and tolerability of this method were assessed in several studies which showed minimal side effects $(165,167-170)$. It is important however to consider parasympathetic activation via taVNS and monitor for cardiac effects (171).
Transcutaneous cervical VNS (tcVNS) is another form of noninvasive VNS that delivers electrical stimulation to the cervical vagus nerve transcutaneously through the neck. Electrodes are placed over the carotid sheath and stimulation is applied with devices that activate the underlying nerve and tissue. tcVNS frequencies range from $5 \mathrm{~Hz}$ to $5 \mathrm{KHz}(172,173)$. A recent paper has proposed, based on two case studies, the use of tcVNS to manage respiratory symptoms in COVID-19 patients (174). They showed that tcVNS decreased the use of opioids and cough suppressant medication, and promoted relief from chest tightness and shortness of breath, improving lung clearance. As both taVNS and tcVNS are very easy to administer and studies have shown they can increase vagus nerve activity, they both are suggested as potential techniques in the treatment of COVID19 patients to control inflammation and decreased respiratory discomfort associated with respiratory symptoms.

\section{Non-invasive Neuromodulation to Target Musculoskeletal Symptoms, Restore Normal Respiration, and Function and to Accelerate Patient Discharge}

Musculoskeletal symptoms in COVID-19 are probably a consequence of systemic inflammation, but a key factor to be addressed, as the musculoskeletal system is strongly related to the capacity to move and perform daily life activities, and probably should be addressed early in the treatment of infected patients. Non-invasive neuromodulation techniques could not only reduce the muscle symptoms present in this population but also improve respiratory muscle function (175-178), training (44, 179-181), and fatigue (182), increasing their motivation, and likely positively affecting the cognitive process, which could aid them in the recovery from the illness.

Respiratory dysfunction is a major concern in COVID-19 (183), with many patients submitted to oxygen support and mechanical ventilation $(184,185)$. It is already known that respiratory dysfunction has a neural correlate which has in part to do with the potential role of the supplementary motor cortex (SMA) in the control of the diaphragm muscle, what has been recently evidenced by the use of TMS (186) and functional magnetic resonance imaging (187). Conditions such as diaphragm loading, and changes in hypoxia and hypercapnia, change transiently diaphragmatic motor-evoked potentials, but these changes may be the source of difficulties in mechanical ventilation weaning.

At present, only one study investigated the effects of mechanical ventilation on cortical excitability and showed that motor-evoked potentials were depressed; one mechanical ventilation was performed non-invasively via nasal mask (188). This result highlights the potential role of mechanical ventilation in depressing CNS excitability and raises the question if failure in weaning from mechanical ventilation has a CNS component. Reports from hospitals struggling with the COVID-19 infection have shown that patients stay $\sim 15-20$ days intubated and in mechanical ventilation and that weaning off is slow (189). It is possible that this exquisite pattern may be due to the invasion of the CNS by the virus, as previously shown. Noninvasive neuromodulation techniques such as tDCS or rTMS 
could be used to help the re-establishment of diaphragmatic drive, but there is still not sufficient evidence to support this use. However, one study has shown that tDCS reduced diaphragmatic motor-evoked potentials (190), which would suggest that stimulation of the motor cortex would not help in mechanical ventilation weaning.

\section{Non-invasive Neuromodulation on Outbreak-Related Mental Distress}

Infectious disease outbreaks pose many challenges to society. As a consequence of fear, stress, social isolation, reduced income, and other factors, psychiatric symptoms may worsen or emerge in those previously asymptomatic people (191). Patients with prior mental illness and frontline healthcare personnel are at an increased risk of psychiatric symptoms during outbreaks (192). Moreover, the impact on mental health on survivors occurs in the long-term, outlasting the pandemic for months to years (193). Non-invasive neuromodulation strategies have been increasingly used as effective clinical interventions in the treatment of diverse neuropsychiatric disorders $(194,195)$. Amongst non-invasive neuromodulation techniques, the most established on clinical grounds is rTMS, an intervention already approved by regulatory agencies for the treatment of major depression in many countries, such as the United States, across the European Union, Israel, Australia, and Brazil (196). Furthermore, rTMS may also be an effective treatment for anxiety and trauma-related disorders, as shown in a recent meta-analysis (PMID: 31066227). One of the major barriers of the broad use of rTMS as mental health interventions is the non-portability of devices. As such, patients need to move to health care facilities, which can be located either in small clinics or in hospitals, to have access to this therapy. Usually, the acute treatment is performed in daily sessions five times a week for some weeks, while the maintenance treatment is more spaced out, with fewer weekly, biweekly, or monthly sessions (197). Since a relevant number of patients that receive rTMS comprise risk groups for COVID-19 severe outcomes (e.g., elderly, smokers, chronic cardiopulmonary diseases), there is a need for session frequency reduction or postponement in those with relatively controlled symptoms, which should be addressed in a case-by-case approach. On the other hand, for hospitals with non-invasive neuromodulation services, rTMS treatment could be offered both for stable COVID-19 inpatients and healthcare personnel, assuring proper measures to control viral transmission are implemented. For inpatients with COVID19 and psychiatric symptoms requiring medical intervention, care must be taken in the prescription of psychotropic drugs if antiviral medications are concomitantly administered, in order to avoid harmful drug-drug interactions (198). Antipsychotics such as risperidone, aripiprazole, and haloperidol (199) and antidepressants such as fluoxetine, paroxetine, sertraline, and duloxetine (200) are metabolized by CYP2D6, the same enzyme that metabolizes chloroquine, a current investigational drug for the management of COVID-19 (201). In this context, the use of NiN would be a safer option.

Standard rTMS protocols for the treatment of psychiatric disorders include high ("excitatory") and low ("inhibitory") frequency trains with coil positioned in the scalp usually over either the right or left DLPFC, according to the indication $(195,198,202)$. Stimulation of the DLPFC can transynaptically enhance activity in the ventromedial prefrontal cortex, which is hypoactive in trauma-related disorders and possibly related to impaired fear responses, a hallmark of these conditions (203). High-frequency rTMS delivered over the right DLPFC has been deemed efficacious for post-traumatic stress disorder (PTSD) in some clinical trials $(195,198,202)$ and would be a reasonable approach to treat patients with traumarelated symptoms. However, in the presence of signs or symptoms that suggest CNS organic compromise, "inhibitory" protocols should be preferred in favor of minimizing the theoretical risk of induced seizures. Low-frequency stimulation of the right DLPFC would be an alternative since one trial that compared both high and low-frequency protocols found no superiority of one intervention over the other in the improvement of PTSD symptoms (204). Furthermore, lowfrequency pulses delivered to the right DLPFC may also be effective for the treatment of generalized anxiety disorder (205). Hence, the choice of the ideal strategy should be guided individually after a careful psychiatric assessment. Since the length of hospital stay for recovered COVID-19 patients is around 21 days (156), rTMS treatment might be continued after discharge in some cases. As neither the immunization (206) nor transmitter status (207) after COVID-19 symptom resolution is clear yet, hygienization procedures and personal protective equipment use should be maintained during further rTMS sessions.

As for the treatment hospital staff, a small sham-controlled trial delivered high-frequency rTMS stimulation over the left DLPFC in healthcare workers diagnosed with occupational stress. Sessions were performed three times a week for 4 weeks, with significant improvement of symptoms at follow-up (208). Another expedite strategy would be to administer intermittent theta-burst stimulation (iTBS) over the right DLPFC, an approach effective for PTSD (209). TBS is a particular type of rTMS that can be performed in shorter sessions (maximum of $10 \mathrm{~min}$ ), minimizing the time that healthcare personnel would need to spend in the NiN sector.

As opposed to rTMS, tDCS could safely be instituted in different environments, including the domestic or ICU setting. However, evidence of tDCS efficacy in anxiety and stress disorders is evolving $(194,210)$. Bifrontal $2 \mathrm{~mA}$ stimulation with cathode over the right and anode over the left DLPFC was performed on a recently published controlled randomized trial, supporting the efficacy of tDCS in the treatment of PTSD (211). In contrast, evidence for tDCS in the treatment of generalized anxiety disorder is less robust (212). A randomized controlled trial showed improvement in physical stress symptoms but not in the primary outcome measure (Hamilton Anxiety Rating Scale) in the active group in comparison to sham (213). Therefore, should tDCS be prescribed, the anode should overlie the left DLPFC with cathode either on the right DLPFC (preferably) or over the right supraorbital area. The current intensity should be set at $2 \mathrm{~mA}$ for $20 \mathrm{~min}$, with 5 or 10 (preferably) daily sessions. 


\section{Home Use of Non-invasive Neuromodulation}

Prior to the COVID-19 pandemic, the availability of homebased non-invasive neuromodulation was already compelling and developed (214-218), especially noting the inconvenience for patients already struggling with debilitating disorders to travel daily for brief non-invasive neuromodulation treatment. Home-use tDCS could also offer an advantage in the context of limited outpatient resources for people living in remote areas (219). Home-base treatment is taken on increasing importance with travel and in-patient treatment severely constrained by the COVID-19 pandemic (e.g., many ill patients confined to the domestic environment).

In the context of clinical care, recommendations for home-based non-invasive neuromodulation involve intervention (device, patient) specific levels of oversight to ensure compliance and tolerability. The remote-supervised tDCS rubric provides specific guidance (16), that is directly applied through the COVID-19 pandemic (218). The need for devices that can be reprogrammed remotely, video-conferencing, and accessories to support reproducible stimulation are all intervention specific considerations. For example, online monitoring with a video conference, so that the supervisor can check the correct positioning of electrodes may be deemed important only a first on-boarding session, for only a few sessions until subject competence is confirmed, or every session $(214,216,220,221)$.

Candidates for home use should receive the device from care providers, along with appropriate training on a physical encounter, to minimize the risk of misuse and overuse (194). Training should cover sponge preparation, electrode placement, stimulation initiation with ramp up until the target intensity, and standard operating procedures for troubleshooting common problems. Customized head-bands that facilitate electrode positioning and improve compliance could also be provided (142, 220, 222). Parameters used in most clinical trials are similar to what is usually employed in care facility settings (220). Therefore, tDCS interventions outlined previously could be recommended for home use (216).

\section{Practical Aspects and Devices Hygienization}

As with all COVID-19 safety procedures, regional and institutional guidance, applied judiciously to specific protocols considering changing conditions, will determine which procedures should be implemented and which should be abbreviated (143). Social/physical distancing parameters as defined by governments and regional regulatory authorities vary and change over time as regional COVID-19 situations evolve. Any recommendations, including the following discussion, is, therefore, region and institute specific, and subject to ongoing risk-burden evaluation. Frequent and adequate hand hygiene is one of the most important measures that should be used to prevent infection by the COVID-19 virus (223). Professionals should perform more frequent and regular hand hygiene, with appropriate techniques (224), including before and after $\mathrm{NiN}$ sessions. In addition, the use of personal protective equipment (PPE) is recommended for the provision of health care with direct contact with infected patients, and include gloves, medical masks, goggles or face shields and gowns, and for specific procedures, respirators and aprons (225).

In inpatient units, the use of an apron is recommended for each suspected case. However, considering that overuse of PPE may impact supplies in situations of shortages (225). Following this rationale, in relation to non-invasive neuromodulation, appropriate protocols should be implemented for the single-use or cleaning or components-this applies not only to accessories that both contact patients (e.g., headgear) but to all surfaces, equipment, and cables (e.g., lead wires from the device). Still, additional precautions should be taken in patients under isolation because of COVID-19 and other infections (e.g., acinetobacter, clostridium), to avoid the risk of cross-infection.

Some essential aspects must be pointed out in relation to the hygiene of non-invasive neuromodulation equipment ${ }^{1}$. The recommended cleaning and disinfection procedures for healthcare equipment must be followed consistently and correctly. In particular, for the disinfection of small surfaces between uses (reusable equipment), the use of $70 \%$ ethyl alcohol is recommended (223). In cases of application of TMS, it may be important to use support for fixing the coil. If another associated intervention is not necessary, the therapist must maintain a distance of at least one meter, always monitoring the session and the patients' signals. We emphasize, as with any COVID-19 safety protocols, the appropriateness of googles, visors, protective visors, and other PPE, and relevant distancing protocols, for specific social and clinical environments, will ultimately be guided by on the current regional and institutional rules.

\section{CONCLUSIONS}

This paper presents empirical evidence, theoretical foundations, and rationale for the potential use of non-invasive neuromodulation techniques such as tDCS, rTMS, taVNS, and tcVNS in the management of COVID-19 related disorders. These techniques may be useful to modulate peripheral and central inflammation response, musculoskeletal and respiratory symptoms, and mental distress associated with COVID-19, even though neuroinvasiveness is still unclear. Thus, the potential benefits of non-invasive neuromodulation should be an important component of ongoing COVID-19 treatment research. Contributing with these international efforts, we made a web-based open-access guideline resource that centralizes all available information related to the use of non-invasive neuromodulation techniques in the management of COVID-19 symptons, including research results and treatment protocols.

\section{AUTHOR CONTRIBUTIONS}

All authors listed have made a substantial, direct and intellectual contribution to the work, and approved it for publication.

\footnotetext{
${ }^{1}$ https://psyarxiv.com/82bmu/ (accessed May 12, 2020).
} 


\section{FUNDING}

AFB, AM, ARB, DCA, KMS, and SKS receive scholarships for scientific production from the Brazilian National Council for Scientific Development (CNPq). AFB, EM, and AO were supported by CEPID/BRAINN-The Brazilian Institute of Neuroscience and Neurotechnology (Process: 13/075593). ARB receives a level $A$ academic scholarship from the University of São Paulo Medical School. INSFB receives a PIC scholarship from UFABC to develop research in the use of noninvasive neuromodulation for the management of COVID-19. MB was supported by grants from the National Institutes of

\section{REFERENCES}

1. Wang C, Horby PW, Hayden FG, Gao GF. A novel coronavirus outbreak of global health concern. Lancet. (2020) 395:4703. doi: 10.1016/S0140-6736(20)30185-9

2. Lake MA. What we know so far: COVID-19 current clinical knowledge and research. Clin Med. (2020) 20:124-7. doi: 10.7861/clinmed.2019-coron

3. World Health Organization. Modes of Transmission of Virus causing COVID19: Implications for IPC Precaution Recommendations: Scientific Brief. World Health Organization (2020). Available at: hts://apps.who.int/iris/handle/ $10665 / 331616$

4. World Health Organization. Coronavirus. (2020). Available online at: https:// www.who.int/health-topics/coronavirus (accessed October 09, 2020).

5. Wang H, Tang X, Fan H, Luo Y, Song Y, Xu Y, et al. Potential mechanisms of hemorrhagic stroke in elderly COVID-19 patients. Aging. (2020) 12:1002234. doi: 10.18632/aging.103335

6. Khan M, Ibrahim RHM, Siddiqi SA, Kerolos YSS, Al-Kaylani MM, Alrukn SAM, et al. COVID-19 and acute ischemic stroke- a case series from Dubai, UAE. Int J Stroke. (2020) 15:699-700. doi: 10.1177/1747493020938285

7. Ye M, Ren Y, Lv T. Encephalitis as a clinical manifestation of COVID-19. Brain Behav Immun. (2020) 88:945-6. doi: 10.1016/j.bbi.2020.04.017

8. Huang YH, Hanna Huang Y, Jiang D, Huang JT. SARS-CoV-2 detected in cerebrospinal fluid by PCR in a case of COVID-19 encephalitis. Brain Behav Immun. (2020) 87:149. doi: 10.1016/j.bbi.2020.05.012

9. Torabi A, Mohammadbagheri E, Akbari Dilmaghani N, Bayat A-H, Fathi $\mathrm{M}$, Vakili K, et al. Proinflammatory cytokines in the olfactory mucosa result in COVID-19 induced Anosmia. ACS Chem Neurosci. (2020) 11:190913. doi: 10.1021/acschemneuro.0c00249

10. Sayad B, Rahimi Z. Blood Coagulation Parameters in Patients with Severe COVID-19. (2020). Available online at: https://assets.researchsquare.com/ files/rs-33368/v1/9f53040e-4bab-41c8-84f7-9e5711435f29.pdf

11. Rosoman N, Gan R. COVID-19 - A Complex Multi-system and Coagulation Disease (2020). Available online at: https://ssrn.com/abstract=3601319

12. Mehta P, McAuley DF, Brown M, Sanchez E, Tattersall RS, Manson JJ. COVID-19: consider cytokine storm syndromes and immunosuppression. Lancet. (2020) 395:1033-4. doi: 10.1016/S0140-6736(20)30628-0

13. Mahmudpour M, Roozbeh J, Keshavarz M, Farrokhi S, Nabipour I. COVID-19 cytokine storm: the anger of inflammation. Cytokine. (2020) 133:155151. doi: 10.1016/j.cyto.2020.155151

14. World Health Organization. Report of the WHO-China Joint Mission on Coronavirus Disease 2019 (COVID-19). World Health Organization (16-24 February 2020). Available online at: https://www.who.int/docs/defaultsource/coronaviruse/who-china-joint-mission-on-covid-19-final-report. pdf (accessed April 8, 2020).

15. Zheng Z, Peng F, Xu B, Zhao J, Liu H, Peng J, et al. Risk factors of critical \& mortal COVID-19 cases: a systematic literature review and meta-analysis. J Infect. (2020) 81:e16-25. doi: 10.1016/j.jinf.2020.04.021

16. Baig AM, Khaleeq A, Ali U, Syeda H. Evidence of the COVID-19 virus targeting the CNS: tissue distribution, host-virus interaction, and
Health: R01NS101362 (MB), R01NS095123 (MB), R01NS112996

(MB), R01MH111896 (MB), R01MH109289 (MB). ACPC and $\mathrm{PS}-\mathrm{O}$ receive $\mathrm{Ph} . \mathrm{D}$. scholarships from the São Paulo Research Foundation/FAPESP (2018/18695-9 and 2019/10760-9, respectively).

\section{ACKNOWLEDGMENTS}

We wish to thank the Brazilian Discussion Group on Noninvasive Neuromodulation and the NAPeN network for the contributions to the discussion about the topics presented in this study.

proposed neurotropic mechanisms. ACS Chem Neurosci. (2020) 11:9958. doi: 10.1021/acschemneuro.0c00122

17. Gu J, Gong E, Zhang B, Zheng J, Gao Z, Zhong Y, et al. Multiple organ infection and the pathogenesis of SARS. J Exp Med. (2005) 202:41524. doi: 10.1084 /jem. 20050828

18. Steardo L, Steardo L Jr, Zorec R, Verkhratsky A. Neuroinfection may contribute to pathophysiology and clinical manifestations of COVID-19. Acta Physiol. (2020) 229:e13473. doi: 10.1111/apha.13473

19. Li Y, Li H, Fan R, Wen B, Zhang J, Cao X, et al. Coronavirus infections in the central nervous system and respiratory tract show distinct features in hospitalized children. Intervirology. (2016) 59:1639. doi: 10.1159/000453066

20. Tracey KJ. The inflammatory reflex. Nature. (2002) 420:8539. doi: 10.1038/nature 01321

21. Desforges M, Le Coupanec A, Dubeau P, Bourgouin A, Lajoie L, Dubé M, et al. Human coronaviruses and other respiratory viruses: underestimated opportunistic pathogens of the central nervous system? Viruses. (2019) 12:14. doi: 10.3390/v12010014

22. Li Y-C, Bai W-Z, Hashikawa T. The neuroinvasive potential of SARS-CoV2 may play a role in the respiratory failure of COVID-19 patients. J Med Virol. (2020) 92:552-5. doi: 10.1002/jmv.25728

23. WHO. Coronavirus. Available online at: www.who.int/emergencies/diseases/ novel-coronavirus-2019 (accessed May 6, 2020).

24. Zhou L, Zhang M, Wang J, Gao J. Sars-Cov-2: underestimated damage to nervous system. Travel Med Infect Dis. (2020) 36:101642. doi: 10.1016/j.tmaid.2020.101642

25. von Weyhern CH, Kaufmann I, Neff F, Kremer M. Early evidence of pronounced brain involvement in fatal COVID-19 outcomes. Lancet. (2020) 395:e109. doi: 10.1016/S0140-6736(20)31282-4

26. Vaseghi G, Mansourian M, Karimi R, Heshmat-Ghahdarijani K, Rouhi P, Shariati M, et al. Inflammatory markers in Covid-19 Patients: a systematic review and meta-analysis. medRxiv [preprint]. (2020). doi: 10.1101/2020.04.29.20084863

27. Zeng F, Guo Y, Yin M, Chen X, Deng G. Association of inflammatory markers with the severity of COVID-19. Int J Infect Dis. (2020) 96:467-74. doi: 10.1016/j.ijid.2020.05.055

28. Del Valle DM, Kim-Schulze S, Hsin-Hui H, Beckmann ND, Nirenberg S, Wang B, et al. An inflammatory cytokine signature helps predict COVID-19 severity and death. medRxiv [preprint]. (2020). doi: 10.1101/2020.05.28.20115758

29. Manjili RH, Zarei M, Habibi M, Manjili MH. COVID-19 as an acute inflammatory disease. J Immunol. (2020) 205:129. doi: 10.4049/jimmunol.2000413

30. Simpson R, Robinson L. Rehabilitation after critical illness in people with COVID-19 infection. Am J Phys Med Rehabil. (2020) 99:4704. doi: 10.1097/PHM.0000000000001443

31. Kalirathinam D, Guruchandran R, Subramani P. Comprehensive physiotherapy management in covid-19 - a narrative review. Sci Med. (2020) 30:38030. doi: 10.15448/1980-6108.2020.1.38030 
32. Abdullahi A. Covid-19 pandemic experience: can it serve as a clarion call to establish or revamp a specialty known as "infectious diseases physiotherapy?” Physiotherapy. (2020) 108:1. doi: 10.1016/j.physio.2020. 05.001

33. Borges do Nascimento IJ, Cacic N, Abdulazeem HM, von Groote TC, Jayarajah U, Weerasekara I, et al. Novel coronavirus infection (COVID19) in humans: a scoping review and meta-analysis. J Clin Med Res. (2020) 9:941. doi: 10.2139/ssrn.3550028

34. Cao Y, Liu X, Xiong L, Cai K. Imaging and clinical features of patients with 2019 novel coronavirus SARS-CoV-2: a systematic review and meta-analysis. J Med Virol. (2020) 92:1449-59. doi: 10.1002/jmv.25822

35. Mudd PA, Crawford JC, Turner JS, Souquette A, Reynolds D, Bender $\mathrm{D}$, et al. Targeted immunosuppression distinguishes COVID-19 from Influenza in moderate and severe disease. MedRxiv [preprint]. (2020). doi: 10.1101/2020.05.28.20115667

36. Regidor P-A. Covid-19 management with inflammation resolving mediators? Perspect Potent. Med Hypotheses. (2020) 142:109813. doi: 10.1016/j.mehy.2020.109813

37. Garg M, Royce SG, Lubel JS. Letter: intestinal inflammation, COVID-19 and gastrointestinal ACE2-exploring RAS inhibitors. Aliment Pharmacol Ther. (2020) 52:571-2. doi: 10.1111/apt.15814

38. Bassi GS, Kanashiro A, Rodrigues GJ, Cunha FQ, Coimbra NC, Ulloa L. Brain stimulation differentially modulates nociception and inflammation in aversive and non-aversive behavioral conditions. Neuroscience. (2018) 383:191-204. doi: 10.1016/j.neuroscience.2018.05.008

39. Liu C-H, Yang M-H, Zhang G-Z, Wang X-X, Li B, Li M, et al. Neural networks and the anti-inflammatory effect of transcutaneous auricular vagus nerve stimulation in depression. J Neuroinflam. (2020) 17:54. doi: 10.1186/s12974-020-01732-5

40. Badran BW, Glusman CE, Badran AW, Austelle CW, DeVries WH, Borckhardt JJ, et al. The physiological and neurobiological effects of transcutaneous auricular vagus nerve stimulation (taVNS). Brain Stimul. (2017) 10:378. doi: 10.1016/j.brs.2017. 01.118

41. Olofsson PS. Vagus nerve stimulation and regulation of inflammation. In: Neuromodulation: Comprehensive Textbook of Principles, Technologies, and Therapies, 2nd Edn. (2018) p. 1483-92. doi: 10.1016/B978-0-12-805353-9.00125-X

42. Rossi S, Santarnecchi E, Valenza G, Ulivelli M. The heart side of brain neuromodulation. Philos Trans A Math Phys Eng Sci. (2016) 374:20150187. doi: 10.1098/rsta.2015.0187

43. Brunoni AR, Chaimani A, Moffa AH, Razza LB, Gattaz WF, Daskalakis ZJ, et al. Repetitive transcranial magnetic stimulation for the acute treatment of major depressive episodes: a systematic review with network metaanalysis. JAMA Psychiatry. (2017) 74:143-52. doi: 10.1001/jamapsychiatry. 2016.3644

44. Morya E, Monte-Silva K, Bikson M, Esmaeilpour Z, Biazoli CE Jr, Fonseca A, et al. Beyond the target area: an integrative view of tDCS-induced motor cortex modulation in patients and athletes. J Neuroeng Rehabil. (2019) 16:141. doi: 10.1186/s12984-019-0581-1

45. Harris-Love ML, Cohen LG. Noninvasive cortical stimulation in neurorehabilitation: a review. Arch Phys Med Rehabil. (2006) 87:S84-93. doi: 10.1016/j.apmr.2006.08.330

46. Saad M, Omrani AS, Baig K, Bahloul A, Elzein F, Matin MA, et al. Clinical aspects and outcomes of 70 patients with Middle East respiratory syndrome coronavirus infection: a single-center experience in Saudi Arabia. Int J Infect Dis. (2014) 29:301-6. doi: 10.1016/j.ijid.2014.09.003

47. Lau K-K, Yu W-C, Chu C-M, Lau S-T, Sheng B, Yuen K-Y. Possible central nervous system infection by SARS coronavirus. Emerg Infect Dis. (2004) 10:342-4. doi: 10.3201/eid1002.030638

48. Kim J-E, Heo J-H, Kim H-O, Song S-H, Park S-S, Park T-H, et al. Neurological complications during treatment of middle east respiratory syndrome. J Clin Neurol. (2017) 13:227. doi: 10.3988/jcn.2017.13.3.227

49. Chiappelli F. Towards Neuro-CoViD-19. Bioinformation. (2020) 16:28892. doi: 10.6026/97320630016288

50. Andries K, Pensaert MB. Immunofluorescence studies on the pathogenesis of hemagglutinating encephalomyelitis virus infection in pigs after oronasal inoculation. Am J Vet Res. (1980) 41:1372-8.
51. Matsuda K, Park CH, Sunden Y, Kimura T, Ochiai K, Kida H, et al. The vagus nerve is one route of transneural invasion for intranasally inoculated influenza a virus in mice. Vet Pathol. (2004) 41:1017. doi: 10.1354/vp.41-2-101

52. Li Y-C, Bai W-Z, Hirano N, Hayashida T, Hashikawa T. Coronavirus infection of rat dorsal root ganglia: ultrastructural characterization of viral replication, transfer, and the early response of satellite cells. Virus Res. (2012) 163:628-35. doi: 10.1016/j.virusres.2011.12.021

53. Arbour N, Côté G, Lachance C, Tardieu M, Cashman NR, Talbot PJ. Acute and persistent infection of human neural cell lines by human coronavirus OC43. J Virol. (1999) 73:3338-50. doi: 10.1128/JVI.73.4.3338-335 0.1999

54. Arbour N, Ekandé S, Côté G, Lachance C, Chagnon F, Tardieu $\mathrm{M}$, et al. Persistent infection of human oligodendrocytic and neuroglial cell lines by human coronavirus 229E. J Virol. (1999) 73:3326-37. doi: 10.1128/JVI.73.4.3326-3337.1999

55. Yamashita M, Yamate M, Li G-M, Ikuta K. Susceptibility of human and rat neural cell lines to infection by SARS-coronavirus. Biochem Biophys Res Commun. (2005) 334:79-85. doi: 10.1016/j.bbrc.2005.06.061

56. Pavlov VA, Tracey KJ. The cholinergic anti-inflammatory pathway. Brain Behav Immun. (2005) 19:493-9. doi: 10.1016/j.bbi.2005.03.015

57. Pavlov VA, Tracey KJ. Controlling inflammation: the cholinergic anti-inflammatory pathway. Biochem Soc Trans. (2006) 34:103740. doi: 10.1042/BST0341037

58. Guyenet PG. Regulation of breathing and autonomic outflows by chemoreceptors. Compr Physiol. (2014) 4:151162. doi: 10.1002/cphy.c140004

59. Zoccal DB, Furuya WI, Bassi M, Colombari DSA, Colombari E. The nucleus of the solitary tract and the coordination of respiratory and sympathetic activities. Front Physiol. (2014) 5:238. doi: 10.3389/fphys.2014.00238

60. Donnelly WT, Bartlett D Jr, Leiter JC. Serotonin in the solitary tract nucleus shortens the laryngeal chemoreflex in anaesthetized neonatal rats. Exp Physiol. (2016) 101:946-61. doi: 10.1113/EP085716

61. Cutsforth-Gregory JK, Benarroch EE. Nucleus of the solitary tract, medullary reflexes, and clinical implications. Neurology. (2017) 88:118796. doi: 10.1212/WNL.0000000000003751

62. Maier SF, Watkins LR. Stressor controllability and learned helplessness: the roles of the dorsal raphe nucleus, serotonin, and corticotropin-releasing factor. Neurosci Biobehav Rev. (2005) 29:829-41. doi: 10.1016/j.neubiorev.2005.03.021

63. Abboud FM, Singh MV. Autonomic regulation of the immune system in cardiovascular diseases. Adv Physiol Educ. (2017) 41:578-93. doi: 10.1152/advan.00061.2017

64. Marvar PJ, Harrison DG. Inflammation, immunity and the autonomic nervous system. In: Robertson D, Biaggioni I, Burnstock G, Low PA, Paton JFR, editors. Primer on the Autonomic Nervous System (Elsevier). p. 3259. doi: 10.1016/B978-0-12-386525-0.00067-6

65. Nance DM, Sanders VM. Autonomic innervation and regulation of the immune system (1987-2007). Brain Behav Immun. (2007) 21:73645. doi: 10.1016/j.bbi.2007.03.008

66. Varatharaj A, Galea I. The blood-brain barrier in systemic inflammation. Brain Behav Immun. (2017) 60:1-12. doi: 10.1016/j.bbi.2016.03.010

67. Mao L, Wang M, Chen S, He Q, Chang J, Hong C, et al. Neurological manifestations of hospitalized patients with COVID-19 in Wuhan, China: a retrospective case series study. JAMA Neurol. (2020) 77:68390. doi: 10.1001/jamaneurol.2020.1127

68. Ding Y, He L, Zhang Q, Huang Z, Che X, Hou J, et al. Organ distribution of severe acute respiratory syndrome (SARS) associated coronavirus (SARS-CoV) in SARS patients: implications for pathogenesis and virus transmission pathways. J Pathol. (2004) 203:622-30. doi: 10.1002/pa th. 1560

69. McCray PB Jr, Pewe L, Wohlford-Lenane C, Hickey M, Manzel L, Shi L, et al. Lethal infection of K18-hACE2 mice infected with severe acute respiratory syndrome coronavirus. J Virol. (2007) 81:813-21. doi: 10.1128/JVI.02 012-06

70. Nilsson A, Edner N, Albert J, Ternhag A. Fatal encephalitis associated with coronavirus OC43 in an immunocompromised child. Infect Dis. (2020) 52:419-22. doi: 10.1080/23744235.2020.1729403 
71. Morfopoulou S, Brown JR, Graham Davies E, Anderson G, Virasami A, Qasim W, et al. Human coronavirus OC43 associated with fatal encephalitis. N Engl J Med. (2016) 375:497-8. doi: 10.1056/NEJMc1509458

72. Turgay C, Emine T, Ozlem K, Muhammet SP, Haydar AT. A rare cause of acute flaccid paralysis: human coronaviruses. J Pediatr Neurosci. (2015) 10:280-1. doi: 10.4103/1817-1745.165716

73. Arabi YM, Harthi A, Hussein J, Bouchama A, Johani S, Hajeer $\mathrm{AH}$, et al. Severe neurologic syndrome associated with Middle East respiratory syndrome corona virus (MERS-CoV). Infection. (2015) 43:495501. doi: 10.1007/s15010-015-0720-y

74. Algahtani H, Subahi A, Shirah B. Neurological complications of middle East respiratory syndrome coronavirus: a report of two cases and review of the literature. Case Rep Neurol Med. (2016) 2016:3502683. doi: 10.1155/2016/3502683

75. Kumar H, Kawai T, Akira S. Pathogen recognition by the innate immune system. Int Rev Immunol. (2011) 30:1634. doi: 10.3109/08830185.2010.529976

76. Barbalat R, Ewald SE, Mouchess ML, Barton GM. Nucleic acid recognition by the innate immune system. Annu Rev Immunol. (2011) 29:185214. doi: 10.1146/annurev-immunol-031210-101340

77. Jarchum I, Pamer EG. Regulation of innate and adaptive immunity by the commensal microbiota. Curr Opin Immunol. (2011) 23:35360. doi: 10.1016/j.coi.2011.03.001

78. Suet Ting Tan R, Lin B, Liu Q, Tucker-Kellogg L, Ho B, Leung BPL, et al. The synergy in cytokine production through MyD88-TRIF pathways is coordinated with ERK phosphorylation in macrophages. Immunol Cell Biol. (2013) 91:377-87. doi: 10.1038/icb.2013.13

79. Li G, Fan Y, Lai Y, Han T, Li Z, Zhou P, et al. Coronavirus infections and immune responses. J Med Virol. (2020) 92:424-32. doi: 10.1002/jmv.25685

80. Yi Y, Lagniton PNP, Ye S, Li E, Xu R-H. COVID-19: what has been learned and to be learned about the novel coronavirus disease. Int J Biol Sci. (2020) 16:1753-66. doi: 10.7150/ijbs.45134

81. Ben Addi A, Lefort A, Hua X, Libert F, Communi D, Ledent C, et al. Modulation of murine dendritic cell function by adenine nucleotides and adenosine: involvement of the $\mathrm{A}(2 \mathrm{~B})$ receptor. Eur J Immunol. (2008) 38:1610-20. doi: 10.1002/eji.200737781

82. Lu X, Pan J 'an, Tao J, Guo D. SARS-CoV nucleocapsid protein antagonizes IFN- $\beta$ response by targeting initial step of IFN- $\beta$ induction pathway, and its C-terminal region is critical for the antagonism. Virus Genes. (2011) 42:37-45. doi: 10.1007/s11262-010-0 544-x

83. Mathern DR, Heeger PS. Molecules great and small: the complement system. Clin J Am Soc Nephrol. (2015) 10:1636-50. doi: 10.2215/CJN.06230614

84. Channappanavar R, Perlman S. Pathogenic human coronavirus infections: causes and consequences of cytokine storm and immunopathology. Semin Immunopathol. (2017) 39:529-39. doi: 10.1007/s00281-017-0629-x

85. Tisoncik JR, Korth MJ, Simmons CP, Farrar J, Martin TR, Katze MG. Into the eye of the cytokine storm. Microbiol Mol Biol Rev. (2012) 76:1632. doi: 10.1128/MMBR.05015-11

86. Ramos I, Fernandez-Sesma A. Cell receptors for influenza a viruses and the innate immune response. Front Microbiol. (2012) 3:117. doi: $10.3389 /$ fmicb.2012.00117

87. McBride WT, Armstrong MA, McBride SJ. Immunomodulation: an important concept in modern anaesthesia. Anaesthesia. (1996) 51:46573. doi: 10.1111/j.1365-2044.1996.tb07793.x

88. Richardson JY, Ottolini MG, Pletneva L, Boukhvalova M, Zhang S, Vogel $\mathrm{SN}$, et al. Respiratory syncytial virus (RSV) infection induces cyclooxygenase 2: a potential target for RSV therapy. J Immunol. (2005) 174:435664. doi: 10.4049/jimmunol.174.7.4356

89. Huang C, Wang Y, Li X, Ren L, Zhao J, Hu Y, et al. Clinical features of patients infected with 2019 novel coronavirus in Wuhan, China. Lancet. (2020) 395:497-506. doi: 10.1016/S0140-6736(20)30183-5

90. Wu Y, Xu X, Chen Z, Duan J, Hashimoto K, Yang L, et al. Nervous system involvement after infection with COVID-19 and other coronaviruses. Brain Behav Immun. (2020) 87:18-22. doi: 10.1016/j.bbi.2020. 03.031

91. Rossi A. Imaging of acute disseminated encephalomyelitis. Neuroimag Clin N Am. (2008) 18:149-61. doi: 10.1016/j.nic.2007.12.007
92. Muhammad S, Haasbach E, Kotchourko M, Strigli A, Krenz A, Ridder DA, et al. Influenza virus infection aggravates stroke outcome. Stroke. (2011) 42:783-91. doi: 10.1161/STROKEAHA.110.596783

93. Dyavanapalli J, Dergacheva O, Wang X, Mendelowitz D. Parasympathetic vagal control of cardiac function. Curr Hypertens Rep. (2016) 18:22. doi: 10.1007/s11906-016-0630-0

94. Mancia G, Grassi G, Tsioufis K, Dominiczak A, Rosei EA. Manual of Hypertension of the European Society of Hypertension. 3rd ed. Boca Raton: CRC Press. (2019). doi: 10.1201/9780429199189

95. Gault J, Robinson M, Berger R, Drebing C, Logel J, Hopkins J, et al. Genomic organization and partial duplication of the human alpha7 neuronal nicotinic acetylcholine receptor gene (CHRNA7). Genomics. (1998) 52:17385. doi: 10.1006/geno.1998.5363

96. Miyazawa A, Fujiyoshi Y, Unwin N. Structure and gating mechanism of the acetylcholine receptor pore. Nature. (2003) 423:949-55. doi: 10.1038/nature01748

97. Chavan SS, Pavlov VA, Tracey KJ. Mechanisms and therapeutic relevance of neuro-immune communication. Immunity. (2017) 46:927-42. doi: 10.1016/j.immuni.2017.06.008

98. Tracey KJ. Reflex control of immunity. Nat Rev Immunol. (2009) 9:41828. doi: $10.1038 /$ nri2566

99. Dalli J, Serhan CN. Immunoresolvents signaling molecules at intersection between the brain and immune system. Curr Opin Immunol. (2018) 50:4854. doi: 10.1016/j.coi.2017.10.007

100. Borovikova LV, Ivanova S, Zhang M, Yang H, Botchkina GI, Watkins LR, et al. Vagus nerve stimulation attenuates the systemic inflammatory response to endotoxin. Nature. (2000) 405:458-62. doi: 10.1038/35013070

101. Matthay MA, Ware LB. Can nicotine treat sepsis? Nat Med. (2004) 10:11612. doi: 10.1038/nm1104-1161

102. Wang H, Liao H, Ochani M, Justiniani M, Lin X, Yang L, et al. Cholinergic agonists inhibit HMGB1 release and improve survival in experimental sepsis. Nat Med. (2004) 10:1216-21. doi: 10.1038/nm1124

103. Ulloa L. The vagus nerve and the nicotinic anti-inflammatory pathway. Nat Rev Drug Discov. (2005) 4:673-84. doi: 10.1038/nrd1797

104. Wang H, Hosiawa KA, Min W, Yang J, Zhang X, Garcia B, et al. Cytokines regulate the pattern of rejection and susceptibility to cyclosporine therapy in different mouse recipient strains after cardiac allografting. J Immunol. (2003) 171:3823-36. doi: 10.4049/jimmunol.171.7.3823

105. Mashimo M, Iwasaki Y, Inoue S, Saito S, Kawashima K, Fujii T. Acetylcholine released from $\mathrm{T}$ cells regulates intracellular Ca 2, IL-2 secretion and T cell proliferation through nicotinic acetylcholine receptor. Life Sciences. (2017) 172:13-8. doi: 10.1016/j.lfs.2016.12.015

106. Fujii T, Mashimo M, Moriwaki Y, Misawa H, Ono S, Horiguchi K, et al. Expression and function of the cholinergic system in immune cells. Front Immunol. (2017) 8:1085. doi: 10.3389/fimmu.2017.01085

107. Lampert R, Bremner JD, Su S, Miller A, Lee F, Cheema F, et al. Decreased heart rate variability is associated with higher levels of inflammation in middle-aged men. Am Heart J. (2008) 156:759.e17. doi: 10.1016/j.ahj.2008.07.009

108. Haensel A, Mills PJ, Nelesen RA, Ziegler MG, Dimsdale JE. The relationship between heart rate variability and inflammatory markers in cardiovascular diseases. Psychoneuroendocrinology. (2008) 33:130512. doi: 10.1016/j.psyneuen.2008.08.007

109. Ghia JE, Blennerhassett P, Kumar-Ondiveeran H, Verdu EF, Collins SM. The vagus nerve: a tonic inhibitory influence associated with inflammatory bowel disease in a murine model. Gastroenterology. (2006) 131:112230. doi: 10.1053/j.gastro.2006.08.016

110. van Westerloo DJ, Giebelen IA, Florquin S, Bruno MJ, Larosa GJ, Ulloa L, et al. The vagus nerve and nicotinic receptors modulate experimental pancreatitis severity in mice. Gastroenterology. (2006) 130:1822-30. doi: 10.1053/j.gastro.2006.02.022

111. Li-Sha G, Xing-Xing C, Lian-Pin W, De-Pu Z, Xiao-Wei L, Jia-Feng $\mathrm{L}$, et al. Right cervical vagotomy aggravates viral myocarditis in mice via the cholinergic anti-inflammatory pathway. Front Pharmacol. (2017) 8:25. doi: 10.3389/fphar.2017.00025

112. Mirakaj V, Dalli J, Granja T, Rosenberger P, Serhan CN. Vagus nerve controls resolution and pro-resolving mediators of inflammation. J Exp Med. (2014) 211:1037-48. doi: 10.1084/jem.20132103 
113. Torres-Rosas R, Yehia G, Peña G, Mishra P, del Rocio Thompson-Bonilla M, Moreno-Eutimio MA, et al. Dopamine mediates vagal modulation of the immune system by electroacupuncture. Nat Med. (2014) 20:2915. doi: 10.1038/nm.3479

114. Yan Y, Jiang W, Liu L, Wang X, Ding C, Tian Z, et al. Dopamine controls systemic inflammation through inhibition of NLRP3 inflammasome. Cell. (2015) 160:62-73. doi: 10.1016/j.cell.2014.11.047

115. Andreis DT, Singer M. Catecholamines for inflammatory shock: a Jekyll-and-Hyde conundrum. Intensive Care Med. (2016) 42:1387-97. doi: 10.1007/s00134-016-4249-z

116. Opal SM, Girard TD, Ely EW. The immunopathogenesis of sepsis in elderly patients. Clin Infect Dis. (2005) 41(Suppl.7):S504-12. doi: 10.1086/432007

117. Smeeth L, Thomas SL, Hall AJ. Risk of myocardial infarction and stroke after acute infection or vaccination. ACC Curr J Rev. (2005) 14:123. doi: 10.1016/j.accreview.2005.02.064

118. Davidson JA, Warren-Gash C. Cardiovascular complications of acute respiratory infections: current research and future directions. Expert Rev Anti Infect Ther. (2019) 17:939-42. doi: 10.1080/14787210.2019.1689817

119. Netland J, Meyerholz DK, Moore S, Cassell M, Perlman S. Severe acute respiratory syndrome coronavirus infection causes neuronal death in the absence of encephalitis in mice transgenic for human ACE2. J Virol. (2008) 82:7264-75. doi: 10.1128/JVI.00737-08

120. Driggin E, Madhavan MV, Bikdeli B, Chuich T, Laracy J, Bondi-Zoccai G, et al. Cardiovascular considerations for patients, health care workers, and health systems during the coronavirus disease 2019 (COVID-19) pandemic. J Am Coll Cardiol. (2020) 75:2352-71.doi: 10.1016/j.jacc.2020.03.031

121. Guo $\mathrm{T}$, Fan $\mathrm{Y}$, Chen $\mathrm{M}$, Wu $\mathrm{X}$, Zhang $\mathrm{L}, \mathrm{He} \mathrm{T}$, et al. Cardiovascular implications of fatal outcomes of patients with coronavirus disease 2019 (COVID-19). JAMA Cardiol. (2020) 5:811-8. doi: 10.1001/jamacardio.2020.1017

122. Wang $M$, Cao $R$, Zhang $L$, Yang $X$, Liu J, Xu $M$, et al. Remdesivir and chloroquine effectively inhibit the recently emerged novel coronavirus (2019-nCoV) in vitro. Cell Res. (2020) 30:269-71. doi: 10.1038/s41422-020-0282-0

123. Sun P, Qie S, Liu Z, Ren J, Li K, Xi J. Clinical characteristics of 50466 hospitalized patients with 2019-nCoV infection. J Med Virol. (2020) 92:6127. doi: 10.1101/2020.02.18.20024539

124. $\mathrm{Ng} \mathrm{W}$, To K, Lam W, Ng T, Lee K. The comparative pathology of severe acute respiratory syndrome and avian influenza A subtype $\mathrm{H} 5 \mathrm{N1}$ - a review. Hum Pathol. (2006) 37:381-90. doi: 10.1016/j.humpath.2006.01.015

125. Leung TW, Wong KS, Hui AC, To KF, Lai ST, Ng WF, et al. Myopathic changes associated with severe acute respiratory syndrome: a postmortem case series. Arch Neurol. (2005) 62:1113-7. doi: 10.1001/archneur.62.7.1113

126. Bo H-X, Li W, Yang Y, Wang Y, Zhang Q, Cheung T, et al. Posttraumatic stress symptoms and attitude toward crisis mental health services among clinically stable patients with COVID-19 in China. Psychol Med. (2020) 1-7. doi: 10.1017/S0033291720000999

127. Liu N, Zhang F, Wei C, Jia Y, Shang Z, Sun L, et al. Prevalence and predictors of PTSS during COVID-19 outbreak in China hardest-hit areas: gender differences matter. Psychiatry Res. (2020) 287:112921. doi: 10.1016/j.psychres.2020.112921

128. Cao W, Fang Z, Hou G, Han M, Xu X, Dong J, et al. The psychological impact of the COVID-19 epidemic on college students in China. Psychiatry Res. (2020) 287:112934. doi: 10.1016/j.psychres.2020.112934

129. Kang L, Ma S, Chen M, Yang J, Wang Y, Li R, et al. Impact on mental health and perceptions of psychological care among medical and nursing staff in Wuhan during the 2019 novel coronavirus disease outbreak: a crosssectional study. Brain Behav Immun. (2020) 87:11-7. doi: 10.1016/j.bbi.2020. 03.028

130. Iseger TA, van Bueren NER, Kenemans JL, Gevirtz R, Arns M. A frontal-vagal network theory for major depressive disorder: implications for optimizing neuromodulation techniques. Brain Stimul. (2020) 13:19. doi: 10.1016/j.brs.2019.10.006

131. Peuker ET, Filler TJ. The nerve supply of the human auricle. Clin Anat. (2002) 15:35-7. doi: 10.1002/ca.1089

132. Hirfanoglu T, Serdaroglu A, Cetin I, Kurt G, Capraz IY, Ekici F, et al. Effects of vagus nerve stimulation on heart rate variability in children with epilepsy. Epilepsy Behav. (2018) 81:33-40. doi: 10.1016/j.yebeh.2018.01.036
133. Balasubramanian K, Harikumar K, Nagaraj N, Pati S. Vagus nerve stimulation modulates complexity of heart rate variability differently during sleep and wakefulness. Ann Indian Acad Neurol. (2017) 20:4037. doi: 10.4103/aian.AIAN_148_17

134. Iseger TA, Padberg F, Kenemans JL, Gevirtz R, Arns M. Neurocardiac-guided TMS (NCG-TMS): probing DLPFC-sgACC-vagus nerve connectivity using heart rate - first results. Brain Stimul. (2017) 10:10068. doi: 10.1016/j.brs.2017.05.002

135. Gianaros PJ, Derbyshire SWG, May JC, Siegle GJ, Gamalo MA, Jennings JR. Anterior cingulate activity correlates with blood pressure during stress. Psychophysiology. (2005) 42:627-35. doi: 10.1111/j.1469-8986.2005.00366.x

136. Critchley HD, Mathias CJ, Josephs O, O'Doherty J, Zanini S, Dewar B-K, et al. Human cingulate cortex and autonomic control: converging neuroimaging and clinical evidence. Brain. (2003) 126:2139-52. doi: 10.1093/brain/awg216

137. Remue J, Vanderhasselt M-A, Baeken C, Rossi V, Tullo J, De Raedt R. The effect of a single HF-rTMS session over the left DLPFC on the physiological stress response as measured by heart rate variability. Neuropsychology. (2016) 30:756-66. doi: 10.1037/neu0000255

138. Vink JJT, Mandija S, Petrov PI, van den Berg CAT, Sommer IEC, Neggers SFW. A novel concurrent TMS-fMRI method to reveal propagation patterns of prefrontal magnetic brain stimulation. Hum Brain Mapp. (2018) 39:458092. doi: 10.1002/hbm.24307

139. Aftanas LI, Gevorgyan MM, Zhanaeva SY, Dzemidovich SS, Kulikova KI, Al'perina EL, et al. Therapeutic effects of repetitive transcranial magnetic stimulation (rTMS) on neuroinflammation and neuroplasticity in patients with parkinson's disease: a placebo-controlled study. Bull Exp Biol Med. (2018) 165:195-9. doi: 10.1007/s10517-018-4128-4

140. Carnevali L, Pattini E, Sgoifo A, Ottaviani C. Effects of prefrontal transcranial direct current stimulation on autonomic and neuroendocrine responses to psychosocial stress in healthy humans. Stress. (2020) 23:2636. doi: 10.1080/10253890.2019.1625884

141. Nikolin S, Boonstra TW, Loo CK, Martin D. Combined effect of prefrontal transcranial direct current stimulation and a working memory task on heart rate variability. PLoS ONE. (2017) 12:e0181833. doi: 10.1371/journal.pone.0181833

142. Borges H, Dufau A, Paneri B, Woods AJ, Knotkova H, Bikson M. Updated technique for reliable, easy, and tolerated transcranial electrical stimulation including transcranial direct current stimulation. J Vis Exp. (2020). doi: 10.3791/59204

143. Bikson M, Hanlon CA, Woods AJ, Gillick BT, Charvet L, Lamm C, et al. Guidelines for TMS/tES clinical services and research through the COVID19 pandemic. Brain Stimul. (2020) 13:1124-49. doi: 10.31234/osf.io/82bmu

144. Perera T, George MS, Grammer G, Janicak PG, Pascual-Leone A, Wirecki TS. The clinical TMS society consensus review and treatment recommendations for TMS therapy for major depressive disorder. Brain Stimul. (2016) 9:33646. doi: 10.1016/j.brs.2016.03.010

145. Oppenheimer SM, Gelb A, Girvin JP, Hachinski VC. Cardiovascular effects of human insular cortex stimulation. Neurology. (1992) 42:1727-32. doi: 10.1212/WNL.42. 9.1727

146. Lane RD, McRae K, Reiman EM, Chen K, Ahern GL, Thayer JF. Neural correlates of heart rate variability during emotion. Neuroimage. (2009) 44:213-22. doi: 10.1016/j.neuroimage.2008.07.056

147. Napadow V, Dhond R, Conti G, Makris N, Brown EN, Barbieri R. Brain correlates of autonomic modulation: combining heart rate variability with fMRI. Neuroimage. (2008) 42:16977. doi: 10.1016/j.neuroimage.2008.04.238

148. Allport LE, Butcher KS, Baird TA, MacGregor L, Desmond $\mathrm{PM}$, Tress BM, et al. Insular cortical ischemia is independently associated with acute stress hyperglycemia. Stroke. (2004) 35:1886-91. doi: 10.1161/01.STR.0000133687.33868.71

149. Williamson JW, Querry R, McColl R, Mathews D. Are decreases in insular regional cerebral blood flow sustained during postexercise hypotension? Med Sci Sports Exerc. (2009) 41:574-80. doi: 10.1249/MSS.0b013e31818 b98c8

150. Williamson JW, McColl R, Mathews D. Changes in regional cerebral blood flow distribution during postexercise hypotension in humans. J Appl Physiol. (2004) 96:719-24. doi: 10.1152/japplphysiol.00911.2003 
151. Kamali A-M, Saadi ZK, Yahyavi S-S, Zarifkar A, Aligholi H, Nami M. Transcranial direct current stimulation to enhance athletic performance outcome in experienced bodybuilders. PLOS ONE. (2019) 14:e0220363. doi: 10.1371/journal.pone.0220363

152. Okano AH, Fontes EB, Montenegro RA, Farinatti P de TV, Cyrino ES, Li LM, et al. Brain stimulation modulates the autonomic nervous system, rating of perceived exertion and performance during maximal exercise. Br J Sports Med. (2015) 49:1213-8. doi: 10.1136/bjsports-2012-091658

153. Okano AH, Machado DGS, Oliveira Neto L, Farias-Junior LF, Agrícola PMD, Arruda A, et al. Can transcranial direct current stimulation modulate psychophysiological response in sedentary men during vigorous aerobic exercise? Int J Sports Med. (2017) 38:493-500. doi: 10.1055/s-0042-121897

154. Piccirillo G, Ottaviani C, Fiorucci C, Petrocchi N, Moscucci F, Di Iorio C, et al. Transcranial direct current stimulation improves the QT variability index and autonomic cardiac control in healthy subjects older than 60 years. Clin Interv Aging. (2016) 11:1687-95. doi: 10.2147/CIA.S116194

155. Montenegro RA, Farinatti P de TV, Fontes EB, Soares PP da S, Cunha FA da, Gurgel JL, et al. Transcranial direct current stimulation influences the cardiac autonomic nervous control. Neurosci Lett. (2011) 497:326. doi: 10.1016/j.neulet.2011.04.019

156. Zhou F, Yu T, Du R, Fan G, Liu Y, Liu Z, et al. Clinical course and risk factors for mortality of adult inpatients with COVID-19 in Wuhan, China: a retrospective cohort study. Lancet. (2020) 395:105462. doi: 10.1016/S0140-6736(20)30566-3

157. Adair D, Truong D, Esmaeilpour Z, Gebodh N, Borges H, Ho L, et al. Electrical stimulation of cranial nerves in cognition and disease. Brain Stimul. (2020) 13:717-50. doi: 10.1016/j.brs.2020.02.019

158. Huston JM, Ochani M, Rosas-Ballina M, Liao H, Ochani K, Pavlov VA, et al. Splenectomy inactivates the cholinergic antiinflammatory pathway during lethal endotoxemia and polymicrobial sepsis. J Exp Med. (2006) 203:1623-8. doi: 10.1084/jem.20052362

159. Peña G, Cai B, Ramos L, Vida G, Deitch EA, Ulloa L. Cholinergic regulatory lymphocytes re-establish neuromodulation of innate immune responses in sepsis. J Immunol. (2011) 187:718-25. doi: 10.4049/jimmunol.1100013

160. Rosas-Ballina M, Olofsson PS, Ochani M, Valdés-Ferrer SI, Levine YA, Reardon C, et al. Acetylcholine-synthesizing T cells relay neural signals in a vagus nerve circuit. Science. (2011) 334:98-101. doi: 10.1126/science.1209985

161. Johnston GR, Webster NR. Cytokines and the immunomodulatory function of the vagus nerve. Br J Anaesth. (2009) 102:453-62. doi: 10.1093/bja/aep037

162. Serhan CN, de la Rosa X, Jouvene C. Novel mediators and mechanisms in the resolution of infectious inflammation: evidence for vagus regulation. J Intern Med. (2019) 286:240-58. doi: 10.1111/joim.12871

163. Serhan CN, Chiang N, Dalli J. New pro-resolving n-3 mediators bridge resolution of infectious inflammation to tissue regeneration. Mol Aspects Med. (2018) 64:1-17. doi: 10.1016/j.mam.2017.08.002

164. Badran BW, Dowdle LT, Mithoefer OJ, LaBate NT, Coatsworth J, Brown JC, et al. Neurophysiologic effects of transcutaneous auricular vagus nerve stimulation (taVNS) via electrical stimulation of the tragus: a concurrent taVNS/fMRI study and review. Brain Stimul. (2018) 11:492500. doi: 10.1016/j.brs.2017.12.009

165. Badran BW, Brown JC, Dowdle LT, Mithoefer OJ, LaBate NT, Coatsworth $\mathrm{J}$, et al. Tragus or cymba conchae? Investigating the anatomical foundation of transcutaneous auricular vagus nerve stimulation (taVNS). Brain Stimul. (2018) 11:947-8. doi: 10.1016/j.brs.2018. 06.003

166. Lamb DG, Porges EC, Lewis GF, Williamson JB. Non-invasive vagal nerve stimulation effects on hyperarousal and autonomic state in patients with posttraumatic stress disorder and history of mild traumatic brain injury: preliminary evidence. Front Med. (2017) 4:124. doi: $10.3389 /$ fmed.2017.00124

167. Kreuzer PM, Landgrebe M, Husser O, Resch M, Schecklmann M, Geisreiter F, et al. Transcutaneous vagus nerve stimulation: retrospective assessment of cardiac safety in a pilot study. Front Psychiatry. (2012) 3:70. doi: 10.3389/fpsyt.2012.00070

168. Kreuzer PM, Landgrebe M, Resch M, Husser O, Schecklmann M, Geisreiter F, et al. Feasibility, safety and efficacy of transcutaneous vagus nerve stimulation in chronic tinnitus: an open pilot study. Brain Stimul. (2014) 7:740-7. doi: 10.1016/j.brs.2014.05.003
169. Redgrave J, Day D, Leung H, Laud PJ, Ali A, Lindert R, et al. Safety and tolerability of transcutaneous vagus nerve stimulation in humans; a systematic review. Brain Stimul. (2018) 11:1225-38. doi: 10.1016/j.brs.2018.08.010

170. Badran BW, Yu AB, Adair D, Mappin G, DeVries WH, Jenkins DD, et al. Laboratory administration of transcutaneous auricular vagus nerve stimulation (taVNS): technique, targeting, and considerations. J Vis Exp. (2019) doi: 10.3791/58984

171. Badran BW, Mithoefer OJ, Summer CE, LaBate NT, Glusman CE, Badran AW, et al. Short trains of transcutaneous auricular vagus nerve stimulation (taVNS) have parameter-specific effects on heart rate. Brain Stimul. (2018) 11:699-708. doi: 10.1016/j.brs.2018.04.004

172. Gurel NZ, Wittbrodt MT, Jung H, Shandhi MH, Driggers EG, Ladd SL, et al. Transcutaneous cervical vagal nerve stimulation blocks sympathetic responses to stress in posttraumatic stress disorder. Psychiatry Clin Psychol. (2020). doi: 10.1101/2020.02.10.20021626

173. Gurel NZ, Huang M, Wittbrodt MT, Jung H, Ladd SL, Shandhi MMH, et al. Quantifying acute physiological biomarkers of transcutaneous cervical vagal nerve stimulation in the context of psychological stress. Brain Stimul. (2020) 13:47-59. doi: 10.1016/j.brs.2019.08.002

174. Staats P, Giannakopoulos G, Blake J, Liebler E, Levy RM. Use of noninvasive vagus nerve stimulation to treat respiratory symptoms associated with COVID-19: a theoretical hypothesis and early clinical experience. Neuromodulation. (2020) 23:784-8. doi: 10.1111/ner.13271

175. Raux M, Xie H, Similowski T, Koski L. Facilitatory conditioning of the supplementary motor area in humans enhances the corticophrenic responsiveness to transcranial magnetic stimulation. J Appl Physiol. (2010) 108:39-46. doi: 10.1152/japplphysiol.91454.2008

176. Rousseau E, Gakwaya S, Melo-Silva CA, Sériès F. Mechanical effects of repetitive transcranial magnetic stimulation of upper airway muscles in awake obstructive sleep apnoea subjects. Exp Physiol. (2015) 100:56676. doi: 10.1113/EP085005

177. Alix-Fages C, Romero-Arenas S, Castro-Alonso M, Colomer-Poveda D, Río-Rodriguez D, Jerez-Martínez A, et al. Short-term effects of anodal transcranial direct current stimulation on endurance and maximal force production. A systematic review and meta-analysis. J Clin Med Res. (2019) 8:536. doi: $10.3390 / \mathrm{jcm} 8040536$

178. Tomczak CR, Greidanus KR, Boliek CA. Modulation of chest wall intermuscular coherence: effects of lung volume excursion and transcranial direct current stimulation. J Neurophysiol. (2013) 110:680-7. doi: 10.1152/jn.00723.2012

179. Ammann C, Spampinato D, Márquez-Ruiz J. Modulating motor learning through transcranial direct-current stimulation: an integrative view. Front Psychol. (2016) 7:1981. doi: 10.3389/fpsyg.2016.01981

180. Demoule A, Verin E, Montcel ST du, Similowski T. Shortterm training-dependent plasticity of the corticospinal diaphragm control in normal humans. Respir Physiol Neurobiol. (2008) 160:172-80. doi: 10.1016/j.resp.2007.09.007

181. Lee D-J, Lee Y-S, Kim H-J, Seo T-H. The effects of exercise training using transcranial direct current stimulation (tDCS) on breathing in patients with chronic stroke patients. J Phys Therapy Sci. (2017) 29:52730. doi: $10.1589 /$ jpts.29.527

182. Lefaucheur J-P, Chalah MA, Mhalla A, Palm U, Ayache SS, Mylius V. The treatment of fatigue by non-invasive brain stimulation. Neurophysiol Clin. (2017) 47:173-84. doi: 10.1016/j.neucli.2017.03.003

183. Wilcox SR. Management of respiratory failure due to covid-19. BMJ. (2020) 369:m1786. doi: 10.1136/bmj.m1786

184. Wu C, Chen X, Cai Y, Xia J 'an, Zhou X, Xu S, et al. Risk factors associated with acute respiratory distress syndrome and death in patients with coronavirus disease 2019 pneumonia in Wuhan, China. JAMA Intern Med. (2020) 180:1-11. doi: 10.1001/jamainternmed.20 20.0994

185. Eastin C, Eastin T. Risk factors associated with acute respiratory distress syndrome and death in patients with coronavirus disease 2019 pneumonia in Wuhan, China. J Emerg Med. (2020) 58:71314. doi: 10.1016/j.jemermed.2020.04.007

186. Laviolette L, Niérat M-C, Hudson AL, Raux M, Allard E, Similowski $\mathrm{T}$. The supplementary motor area exerts a tonic excitatory influence on 
corticospinal projections to phrenic motoneurons in awake humans. PLoS ONE. (2013) 8:e62258. doi: 10.1371/journal.pone.0062258

187. Nakayama T, Fujii Y, Suzuki K, Kanazawa I, Nakada T. The primary motor area for voluntary diaphragmatic motion identified by high field fMRI. $J$ Neurol. (2004) 251:730-5. doi: 10.1007/s00415-004-0413-4

188. Sharshar T, Ross ET, Hopkinson NS, Porcher R, Nickol AH, Jonville $S$, et al. Depression of diaphragm motor cortex excitability during mechanical ventilation. J Appl Physiol. (2004) 97:3-10. doi: 10.1152/japplphysiol.01099.2003

189. Rosenbaum L. Facing covid-19 in italy - ethics, logistics, and therapeutics on the epidemic's front line. $N$ Engl J Med. (2020) 382:1873-5. doi: 10.1056/NEJMp2005492

190. Azabou E, Roche N, Sharshar T, Bussel B, Lofaso F, Petitjean M. Transcranial direct-current stimulation reduced the excitability of diaphragmatic corticospinal pathways whatever the polarity used. Respir Physiol Neurobiol. (2013) 189:183-7. doi: 10.1016/j.resp.2013.07.024

191. Brooks SK, Webster RK, Smith LE, Woodland L, Wessely S, Greenberg $\mathrm{N}$, et al. The psychological impact of quarantine and how to reduce it: rapid review of the evidence. Lancet. (2020) 395:912-20. doi: 10.1016/S0140-6736(20)30460-8

192. Jeong H, Yim HW, Song Y-J, Ki M, Min J-A, Cho J, et al. Mental health status of people isolated due to Middle East respiratory syndrome. Epidemiol Health. (2016) 38:e2016048. doi: 10.4178/epih.e2016048

193. Mak IWC, Chu CM, Pan PC, Yiu MGC, Ho SC, Chan VL. Risk factors for chronic post-traumatic stress disorder (PTSD) in SARS survivors. Gen Hosp Psychiatry. (2010) 32:590-8. doi: 10.1016/j.genhosppsych.2010.07.007

194. Lefaucheur J-P, Antal A, Ayache SS, Benninger DH, Brunelin J, Cogiamanian F, et al. Evidence-based guidelines on the therapeutic use of transcranial direct current stimulation (tDCS). Clin Neurophysiol. (2017) 128:5692. doi: 10.1016/j.clinph.2016.10.087

195. Lefaucheur J-P, Aleman A, Baeken C, Benninger DH, Brunelin J, Di Lazzaro $\mathrm{V}$, et al. Evidence-based guidelines on the therapeutic use of repetitive transcranial magnetic stimulation (rTMS): an update (2014-2018). Clin Neurophysiol. (2020) 131:474-528. doi: 10.1016/j.clinph.2020.02.003

196. Brunoni AR, Sampaio-Junior B, Moffa AH, Aparício LV, Gordon P, Klein I, et al. Noninvasive brain stimulation in psychiatric disorders: a primer. Braz J Psychiatry. (2019) 41:70-81. doi: 10.1590/1516-4446-2017-0018

197. Milev RV, Giacobbe P, Kennedy SH, Blumberger DM, Daskalakis ZJ, Downar J, et al. Canadian network for mood and anxiety treatments (CANMAT) 2016 clinical guidelines for the management of adults with major depressive disorder: section 4. neurostimulation treatments. Can J Psychiatry. (2016) 61:561-75. doi: 10.1177/0706743716660033

198. Zhang K, Zhou X, Liu H, Hashimoto K. Treatment concerns for psychiatric symptoms in COVID-19-infected patients with or without psychiatric disorders. Br J Psychiatry. (2020) 9:1. doi: 10.1192/bjp.2020.84

199. van Westrhenen R, Aitchison KJ, Ingelman-Sundberg M, Jukić MM. Pharmacogenomics of antidepressant and antipsychotic treatment: how far have we got and where are we going? Front Psychiatry. (2020) 11:94. doi: 10.3389/fpsyt.2020.00094

200. Cazet L, Bulteau S, Evin A, Spiers A, Caillet P, Kuhn E, et al. Interaction between CYP2D6 inhibitor antidepressants and codeine: is this relevant? Expert Opin Drug Metab Toxicol. (2018) 14:87986. doi: 10.1080/17425255.2018.1496236

201. Barlow A, Landolf KM, Barlow B, Yeung SYA, Heavner JJ, Claassen CW, et al. Review of emerging pharmacotherapy for the treatment of coronavirus disease 2019. Pharmacotherapy. (2020) 40:416-37. doi: 10.1002/phar.2398

202. Ahmadizadeh M-J, Rezaei M. Unilateral right and bilateral dorsolateral prefrontal cortex transcranial magnetic stimulation in treatment posttraumatic stress disorder: a randomized controlled study. Brain Res Bull. (2018) 140:334-40. doi: 10.1016/j.brainresbull.2018.06.001

203. Marin M-F, Camprodon JA, Dougherty DD, Milad MR. Device-based brain stimulation to augment fear extinction: implications for PTSD treatment and beyond. Depress Anxiety. (2014) 31:269-78. doi: 10.1002/da.22252

204. Kozel FA, Van Trees K, Larson V, Phillips S, Hashimie J, Gadbois $\mathrm{B}$, et al. One hertz versus ten hertz repetitive TMS treatment of PTSD: a randomized clinical trial. Psychiatry Res. (2019) 273:15362. doi: 10.1016/j.psychres.2019.01.004
205. Rodrigues PA, Zaninotto AL, Neville IS, Hayashi CY, Brunoni AR, Teixeira MJ, et al. Transcranial magnetic stimulation for the treatment of anxiety disorder. Neuropsychiatr Dis Treat. (2019) 15:2743-61. doi: 10.2147/NDT.S201407

206. Lin Q, Zhu L, Ni Z, Meng H, You L. Duration of serum neutralizing antibodies for SARS-CoV-2: lessons from SARS-CoV infection. J Microbiol Immunol Infect. (2020) 53:821-2. doi: 10.1016/j.jmii.2020.03.015

207. Chen D, Xu W, Lei Z, Huang Z, Liu J, Gao Z, et al. Recurrence of positive SARS-CoV-2 RNA in COVID-19: a case report. Int J Infect Dis. (2020) 93:297-9. doi: 10.1016/j.ijid.2020.03.003

208. Kim YI, Kim SM, Kim H, Han DH. The effect of high-frequency repetitive transcranial magnetic stimulation on occupational stress among health care workers: a pilot study. Psychiatry Investig. (2016) 13:6229. doi: 10.4306/pi.2016.13.6.622

209. Philip NS, Barredo J, Aiken E, Larson V, Jones RN, Shea MT, et al. Thetaburst transcranial magnetic stimulation for posttraumatic stress disorder. Am J Psychiatry. (2019) 176:939-48. doi: 10.1176/appi.ajp.2019.18101160

210. D’Urso G, Mantovani A, Patti S, Toscano E, de Bartolomeis A. Transcranial direct current stimulation in obsessive-compulsive disorder, posttraumatic stress disorder, and anxiety disorders. J ECT. (2018) 34:17281. doi: 10.1097/YCT.0000000000000538

211. Ahmadizadeh MJ, Rezaei M, Fitzgerald PB. Transcranial direct current stimulation (tDCS) for post-traumatic stress disorder (PTSD): a randomized, double-blinded, controlled trial. Brain Res Bull. (2019) 153:273-8. doi: 10.1016/j.brainresbull.2019.09.011

212. Stein DJ, Fernandes Medeiros L, Caumo W, Torres IL. Transcranial direct current stimulation in patients with anxiety: current perspectives. Neuropsychiatr Dis Treat. (2020) 16:161-9. doi: 10.2147/NDT.S195840

213. de Lima AL, Braga FMA, da Costa RMM, Gomes EP, Brunoni AR, Pegado R. Transcranial direct current stimulation for the treatment of generalized anxiety disorder: a randomized clinical trial. J Affect Disord. (2019) 259:317. doi: $10.1016 /$ j.jad.2019.08.020

214. Riggs A, Patel V, Paneri B, Portenoy RK, Bikson M, Knotkova H. At-home transcranial direct current stimulation (tDCS) with telehealth support for symptom control in chronically-Ill patients with multiple symptoms. Front Behav Neurosci. (2018) 12:93. doi: 10.3389/fnbeh.2018.00093

215. Alonzo A, Fong J, Ball N, Martin D, Chand N, Loo C. Pilot trial of homeadministered transcranial direct current stimulation for the treatment of depression. J Affect Disord. (2019) 252:475-83. doi: 10.1016/j.jad.2019.04.041

216. Charvet LE, Shaw MT, Bikson M, Woods AJ, Knotkova H. Supervised transcranial direct current stimulation (tDCS) at home: a guide for clinical research and practice. Brain Stimul. (2020) 13:686-93. doi: 10.1016/j.brs.2020.02.011

217. Dobbs B, Pawlak N, Biagioni M, Agarwal S, Shaw M, Pilloni G, et al. Generalizing remotely supervised transcranial direct current stimulation (tDCS): feasibility and benefit in Parkinson's disease. $J$ Neuroeng Rehabil. (2018) 15:114. doi: 10.1186/s12984-018-0 457-9

218. Charvet LE, Kasschau M, Datta A, Knotkova H, Stevens MC, Alonzo A, et al. Remotely-supervised transcranial direct current stimulation (tDCS) for clinical trials: guidelines for technology and protocols. Front Syst Neurosci. (2015) 9:26. doi: 10.3389/fnsys.2015.00026

219. Palm U, Kumpf U, Behler N, Wulf L, Kirsch B, Wörsching J, et al. Home use, remotely supervised, and remotely controlled transcranial direct current stimulation: a systematic review of the available evidence. Neuromodulation. (2018) 21:323-33. doi: 10.1111/ner.12686

220. Sandran N, Hillier S, Hordacre B. Strategies to implement and monitor in-home transcranial electrical stimulation in neurological and psychiatric patient populations: a systematic review. J Neuroeng Rehabil. (2019) 16:58. doi: 10.1186/s12984-019-0529-5

221. Shaw M, Pilloni G, Charvet L. Delivering transcranial direct current stimulation away from clinic: remotely supervised tDCS. Mil Med. (2020) 185:319-25. doi: 10.1093/milmed/usz348

222. Knotkova H, Riggs A, Berisha D, Borges H, Bernstein H, Patel V, et al. Automatic M1-SO montage headgear for transcranial direct current stimulation (TDCS) suitable for home and high-throughput in-clinic applications. Neuromodulation. (2019) 22:904-10. doi: 10.1111/ner.12786 
223. World Health Organization. Water, Sanitation, Hygiene, and Waste Management for the COVID-19 Virus. World Health Organization (2020). Available online at: https://www.who.int/publications/ i/item/water-sanitation-hygiene-and-waste-management-for-the-covid19-virus-interim-guidance (accessed October 9, 2020).

224. World Health Organization. WHO Guidelines on Hand Hygiene in Health Care: First Global Patient Safety Challenge Clean Care Is Safer Care. Geneva: World Health Organization (2013).

225. World Health Organization. Rational Use of Personal Protective Equipment for Coronavirus Disease (COVID-19): Interim Guidance, 27 February 2020. World Health Organization (2020). Available online at: https://apps.who.int/ iris/handle/10665/331215

Conflict of Interest: AFB and KMS are an instructor at the non-invasive neuromodulation course of São Paulo University (USP)/Brazilian Association of Neurofunctional Physiotherapy (ABRAFIN)/NAPeN. BB is listed as an inventor on brain stimulation patents assigned to the Medical University of South Carolina, has equity in Bodhi NeuroTech, Inc. KMS is the coordinator of the non-invasive neuromodulation course of São Paulo University (USP)/Brazilian Association of
Neurofunctional Physiotherapy (ABRAFIN)/NAPeN. The City University of New York holds patents on brain stimulation with $\mathrm{MB}$ as inventor, has equity in Soterix Medical Inc., consults, received grants, assigned inventions, and/or serves on the $\mathrm{SAB}$ of Boston Scientific, GlaxoSmithKline, Mecta, Halo Neuroscience, X.

The remaining authors declare that the research was conducted in the absence of any commercial or financial relationships that could be construed as a potential conflict of interest.

Copyright (c) 2020 Baptista, Baltar, Okano, Moreira, Campos, Fernandes, Brunoni, Badran, Tanaka, de Andrade, da Silva Machado, Morya, Trujillo, Swami Camprodon, Monte-Silva, Sá, Nunes, Goulardins, Bikson, Sudbrack-Oliveira, de Carvalho, Duarte-Moreira, Pagano, Shinjo and Zana. This is an open-access article distributed under the terms of the Creative Commons Attribution License (CC BY). The use, distribution or reproduction in other forums is permitted, provided the original author(s) and the copyright owner(s) are credited and that the original publication in this journal is cited, in accordance with accepted academic practice. No use, distribution or reproduction is permitted which does not comply with these terms. 